\title{
Parâmetros de projeto e métodos visuais APOs: estudo de duas escolas no Reino Unido
}

\author{
Design patternsand visual methodsPOEs: study in \\ twoschools in the UK
}

\section{Larissa Negris de Souza \\ DorisCatharineCornelieKnatz Kowaltowski Pamela Woolner}

Resumo

programa arquitetônico inclui fase de levantamento de dados que auxiliam na proposição do projeto. Diversos métodos para a coleta e análise desses dados são associados à avaliação pós-ocupação (APO), com observações e medições do projetista/pesquisador e percepções dos usuários sobre ambientes. A APO em escolas busca compreender esses espaços, que impactam no desenvolvimento das atividades de ensino/aprendizagem. O conceito de parâmetros de projeto (PPs) do século XXI deve ser considerado. Este estudo, exploratório, avaliou a aplicação de dois métodos visuais na APO, em escolas do Reino Unido, para retroalimentação de projetos, incluindo PPs como critério de avaliação. O diamond ranking, para análise de imagens, e análise de plantas, para indicação de observações, por meio de adesivos, pelos usuários. O resultado principal é a comprovação da eficácia de métodos visuais no desenvolvimento do programa e APO, fornecendo informações mais completas e ativando maior interesse na participação dos usuários. A seleção de imagens e a aplicação das ferramentas, validadas pela análise e compreensão de respostas, tiveram como base os PPs. Nas discussões de critérios e requisitos para a arquitetura escolar do século XXI, o desenvolvimento de métodos visuais para APO de escolas é visto como uma contribuição importante metodológica e conceitual.

Palavras-chave: Avaliação pós-ocupação. Arquitetura escolar. Programa arquitetônico. Parâmetros de projeto. Métodos visuais.

\begin{abstract}
The architectural programme process includes a data-gathering phase that assists in the development of design propositions. Numerous methods exist for the collection and analysis of this data, related to Post-Occupancy Evaluation (POE), with observations and measurements by the designer/researcher and perceptions by users about places. POE in schools seeks to understand these environments, which impact the quality of teaching/learning activities. Educational dynamics demand the consideration of the concept of 21st-century design patterns (DPs). This exploratory study evaluated twovisual methods in POE, in schools of the UK, for design feedback, which include DPs as evaluation criteria. The methodsevaluatedwere:diamondranking, for image analysis, and floor plans analysis, with observations indicated by users, with stickers. The results showed these visual methods to be effective for briefing and POE. The methods provide better information, and users demonstrate greater interest in participating. The selection of images and the application of the visual tools are based on DPs, validated by the analysis and response comprehension. The development of visual methods for school POEs, with DPs insertion, is a methodological and conceptual contribution that discusses essential characteristics for 21 st-century school architecture.
\end{abstract}

${ }^{1}$ Larissa Negris de Souza 'Universidade Estadual de Campinas Campinas - SP - Brasil

${ }^{2}$ Doris Catharine CornelieKnatzKowaltowski ${ }^{2}$ Universidade Estadual de Campinas Campinas - SP - Brasil

\footnotetext{
${ }^{3}$ Pamela Woolner ${ }^{3}$ Newscastle University Newcastle upon Tyne -UK

Recebido em 05/12/19 Aceito em 23/3/20
}

Keywords: Post-occupancy evaluation. School architecture. Architectural programming. Design patterns. Visual methods. 


\section{Introdução}

O processo de projeto possui fases tradicionalmente denominadas análise, síntese e avaliação. A fase de análise inclui, entre outras atividades, a elaboração de um programa arquitetônico (WHITE, 1972; KUMLIN, 1995; MOREIRA, 2007; KOWALTOWSKI; MOREIRA, 2011; LAWSON, 2011; VAN DER VOORDT; VAN WEGEN, 2013). Para desenvolver um programa que apoie a busca de soluções projetuais apropriadas é necessário levantar dados de experiências anteriores, através da avaliação pós-ocupação (APO). Essa coleta, relativa ao uso e funcionamento de edifícios, deve ser feita com foco nas observações e medições do pesquisador e nas percepções pelos usuários. Originam-se daí diagnósticos e recomendações para o objeto de avaliação ou futuros projetos (ONO et al., 2018).

Interações antes não previstas em projeto também são compreendidas a partir da APO, e passa-se a entender com maior profundidade a experiência do usuário. A análise dessas informações retroalimenta a próxima fase do processo de projeto, com impacto nos critérios projetuais (ORNSTEIN et al., 2009; CLEMENTSCROOME, 2018). Algumas metodologias de levantamento de dados podem ser aplicadas na APO, como os métodos visuais, que são formas de estímulo à participação ativa dos usuários (CLARK et al., 2013).

As APOs em escolas, especificamente, são essenciais, uma vez que a escola é um equipamento de grande importância para a sociedade e para a comunidade em que se insere. Além da participação e da opinião dos usuários, deve-se ter em mente que a arquitetura escolar do século XXI é impactada pelas dinâmicas educacionais, cujas configurações podem ser expressas por meio dosparâmetros de projeto (PPs) de Nair, Fielding e Lackney (2013). Esses parâmetros são orientações gerais das características escolares que precisam ser consideradas também durante a realização de APOs, uma vez que definem o conteúdo a ser avaliado e os tipos de protocolos. Na fase do programa arquitetônico os PPs fornecem subsídios para a avaliação de propostas e para decisões projetuais a serem tomadas.

Este artigo tem como objetivo avaliar a utilização de métodos visuais em APO e retroalimentação de projetos, aprimorando essas metodologias com a inclusão dos PPs como critério de avaliação. Os métodos visuais aplicados nos estudos de caso foram desenvolvidos pelo grupo de pesquisa CfLaT (Research Centre for Learning and Teaching), da Universidade de Newcastle, Reino Unido ${ }^{1}$. Algumas questões direcionaram a pesquisa: é possível associar o conceito dos novos PPs escolares à métodos visuais de APO? Há espaço para expansão dos instrumentos usados para pesquisas em APO, especificamente relacionados aos métodos visuais?

\section{APO no processo de projeto}

A APO começou a ser discutida, em âmbito internacional, nos anos 1940, colocando a edificação sob destaque através de uma perspectiva do usuário e não apenas como objeto físico. O início da abordagem do tema, no pós-Segunda Guerra nos Estados Unidos, foi intrinsecamente ligado à psicologia. Em 2005, a APO foi inserida em um sistema ampliado de gestão da qualidade do ambiente construído, com mudança de terminologia para avaliação de desempenho da construção (building performance evaluation - BPE) por Preiser e Vischer, representando sua multidisciplinaridade e aplicação de multimétodos (ONO et al., 2018).

No Brasil a APO teve suas primeiras pesquisas fundamentadas nos anos 1970, com foco em edifícios habitacionais. Sua consolidação foi a partir da década de 1980, tendo seus procedimentos metodológicos aperfeiçoados na primeira década no século XXI. Nesse momento foram acrescentados aspectos relacionados ao conforto ambiental e desempenho do ambiente construído. Além disso, tendências do Brasil e do mundo buscam incorporar novos meios ligados à tecnologia da informação como forma de aprimorar as ferramentas de avaliação e acesso a resultados.

A APO diz respeito a um conjunto de procedimentos metodológicos. A escolha dos métodos incluídos em um estudo de APO ocorre a partir da delimitação de objetivos da análise, ou o tipo de informações a ser levantada. A abordagem com métodos distintos permite a coleta de aspectos relacionados ao uso e às observações dos usuários sob diferentes perspectivas. Nesse contexto importa que sejam realizadas avaliações continuadas, que contribuem não só para retrofits específicos, mas também para melhorias em novos projetos. Com a APO são incluídos diagnósticos de conforto ambiental, considerando análises em

${ }^{1}$ Uma das autoras desenvolveu um estágio de pesquisa nesse centro de pesquisa durante seu mestrado para ganhar conhecimento sobre os recentes esforços nas escolas públicas do Reino Unido de alinhar sua arquitetura aos conceitos da educação do século XXI. 0 estágio permitiu também conhecer e aplicar métodos visuais de APO desenvolvidos pelo CfLaT, o que apoiou a pesquisa de mestrado no país, na qual se criarammétodos visuais específicos.

200 Souza, L. N. de; Kowaltowski, D. C. C. K.; Woolner, P. 
desempenho acústico, térmico, luminoso e funcional, que posteriormente darão suporte ao programa arquitetônico e à definição de indicadores de avaliação de propostas (FRANÇA, 2011; LAWSON, 2011; VAN DER VOORDT; VAN WEGEN, 2013).

\section{APO para escolas}

Edifícios institucionais apresentam grande relevância na avaliação do seu desempenho por fazerem parte de um sistema maior de projetos similares e retroalimentação de informações. $O$ edifício escolar, diferentemente da maior parte dos edifícios institucionais, possui a maior parte de sua população como fixa. Isso significa que os usuários convivem com os espaços escolares diariamente, e por anos, e estes afetam seu bem-estar, suas percepções e sua produtividade (AZEVEDO, 2012; BARRETT et al., 2016; ONO et al., 2018; SOUZA, 2018).

Dessa forma, as dinâmicas na educação impactam o ambiente físico da escola, ao mesmo tempo em que as modificações desses ambientes devem contribuir positivamente para o desenvolvimento das atividades pedagógicas de ensino/aprendizagem (DELIBERADOR, 2016; VELOSO; MARQUES, 2017; LE et al., 2018). Para um espaço adequado à época em que se insere, com respeito às necessidades individuais e do grupo, é preciso um processo de projeto que valorize a participação desses atores. Essa participação pode acontecer no desenvolvimento do programa arquitetônico, mas também no período de ocupação dos ocupados, buscando entender o uso e a percepção do espaço.

Dessa forma, as APOs têm se mostrado importantes aliadas na busca de qualidade de projetos escolares novos, ou na proposta de reforma desses tipos de edificações. O objetivo, nesse caso, é realizar projetos escolares cada vez mais próximos às demandas da geração de usuários dos espaços do século XXI (SOUZA, 2018). Por esse motivo é importante a inclusão dos novos parâmetros de projeto, tais como desenvolvidos por Nair, Fielding e Lackney (2013), nessa etapa, como requisito de observações e análises e inclusão nas decisões de projeto.

\section{Parâmetros de projeto}

As edificações escolares são influenciadas por uma série de fatores práticos e tecnológicos, bem como por tendências de projeto relacionados às políticas públicas (WOOLNER et al., 2007). Atualmente também há uma busca constante de se distanciar do perfil e organização espacial das escolas do século XVIII e XIX, de modo que se aproximem das novas considerações sobre aprendizado (AZEVEDO; BASTOS; BLOWER, 2007) que vêm a modificar os parâmetros utilizados na educação. Para Souza (2018), uma nova linguagem de parâmetros indica uma expressão clara de características específicas, necessárias e desejadas para as escolas do século XXI.

Por sua vez, Dudek (2000) e Taylor (2009) criticam as edificações educacionais que priorizam considerações técnicas - normas, metragem quadrada, eficiência energética -, deixando em segundo plano questões estéticas e discussões que incluem criatividade e imaginação. Kowaltowski (2011) acrescenta que, ao longo do projeto, obra, manutenção e uso de uma edificação escolar, é necessário que se reflita sobre os objetivos do edifício: experiências espaciais estéticas, de ser convidativo e confortável, com adaptação contextuais e pedagógicas, entre outros fatores.

Nesse sentido os 29 PPs escolares definidos por Nair, Fielding e Lackney (2013) e estudados em profundidade por Souza (2018) vêm a auxiliar o projeto de edificações escolares (Quadro 1). Sua base conceitual está nos patterns de Alexander, Ishikawa e Silverstein (1977): soluções de problemas recorrentes, aplicados incontáveis vezes sem nunca serem repetidos pela maneira de uso. Esses parâmetros também podem ser vistos como orientações das características do objeto durante o processo de projeto, e são respostas funcionais ao problema colocado (MOREIRA, 2007).

Ao se trabalhar com os novos PPs, leva-se em consideração, principalmente, a existência de ambientes de ensino mais flexíveis e adaptáveis. Transformam-se conceitos clássicos de salas de aula, refeitório, espaços de uso comum. Características como transparência, iluminação, acústica e elementos de sustentabilidade também são reavaliadas e devem ser consideradas pela combinação de sua funcionalidade, desempenho e preocupações psicológicos e de bem-estar. 
Quadro 1 - Parâmetros de projeto deNair, Fielding e Lackney (2013)

\begin{tabular}{|l|l|}
\hline $\begin{array}{l}\text { 1. Salas de aula, ambientes de ensino e } \\
\text { comunidades pequenas de aprendizado }\end{array}$ & $\begin{array}{l}\text { 16. Wateringholespace(locais para estudo em } \\
\text { pequenos grupos) }\end{array}$ \\
\hline 2. Entrada convidativa & $\begin{array}{l}\text { 17. Cave space (locais para o estudo individual ou } \\
\text { introspecção) }\end{array}$ \\
\hline 3. Espaços de exposição dos trabalhos dos alunos & 18. Projeto para múltiplas inteligências* \\
\hline $\begin{array}{l}\text { 4. Espaço individual para armazenamento de } \\
\text { materiais }\end{array}$ & 19. Iluminação natural \\
\hline 5. Laboratórios de ciências e artes & 20. Ventilação natural \\
\hline 6. Arte, música e atuação & 21. Iluminação, cor e aprendizagem \\
\hline 7. Área de educação física & 22. Elementos de sustentabilidade \\
\hline 8. Áreas casuais de alimentação & 23. Assinatura local \\
\hline 9. Transparência & 24. Conexão com a comunidade \\
\hline 10. Vistas interiores e exteriores & 25. Banheiros como os de casa \\
\hline 11. Tecnologia distribuída & 26. Professores como profissionais \\
\hline 12. Conexão entre espaços externos e internos & $\begin{array}{l}\text { 27. Recursos de aprendizado compartilhados e } \\
\text { biblioteca }\end{array}$ \\
\hline 13. Mobiliários confortáveis & 28. Proteção e segurança \\
\hline 14. Espaços flexíveis & 29. Síntese dos parâmetros \\
\hline $\begin{array}{l}\text { 15. Campfirespace(locais para reunião de grandes } \\
\text { grupos, palestras, aulas teóricas expositivas) }\end{array}$ & \\
\hline
\end{tabular}

Nota: *considera-se que existem oito inteligências: verbal-linguística, lógico-matemática, musical, corporal-cinestésica, visual-espacial, naturalista, interpessoal, intrapessoal (GARDNER, 2006).

\section{Método}

A pesquisa, exploratória, realizada em 2017, aplicou instrumentos metodológicos de caráter quantitativo e qualitativo em estudos de casos em duas escolas (E1 e E2) de ensino fundamental II - EFII (Secondary Schools) no Reino Unido ${ }^{2}$. As coletas de dados foram acompanhadas pelo CfLaT e realizadas de acordo com as regulamentações dos comitês de ética do Reino Unido. Em cada caso foi aplicada uma combinação de técnicas de coleta de dados diferente, apontando distintas possibilidades de abordagens para APO em edifícios escolares. O Quadro 2 apresenta um resumo sobre os métodos utilizados e sua construção foi baseda na tabela "Instrumentos adotados para a pesquisa" de Ono et al. (2018, p. 185).

Os métodos de avaliação apresentados podem ser aplicados em conjunto, seguindo a ordem descrita na tabela, ou separadamente, como se observa neste estudo, mas ainda assim funcionando de modo complementar para resultados em longo prazo. A escolha da combinação metodológica depende de fatores como a definição do objeto e objetivos de pesquisa, as possibilidades de aplicação e limitações dos instrumentos e do estudo de caso (limitações temporais, disponibilidade de participantes, permissões de acesso, entre outras).

\section{Walkthrough}

O walkthrough é um instrumento básico de reconhecimento de ambientes, quando são feitas as coletas de dados iniciais, acompanhadas de um usuário do espaço que possua conhecimento sobre seu funcionamento. Ao longo do percurso é estabelecida uma conversa para trocar informações técnicas e de ocupação, além de serem observadas características arquitetônicas (nesse caso, baseadas nos PPs). Nesse momento, é possível que sejam feitos registros visuais, como fotografias, previamente acordados. Nesta pesquisa, o walkthrough foi realizado em ambientes internos e externos das duas escolas, e as fotografias foram permitidas apenas com ambientes vazios. As primeiras visitas à E1 foram realizadas acompanhadas de um dos membros da local authority (órgão encarregado pelo gerenciamento e orçamento de escolas, agrupadas por região). A primeira visita à E2 foi acompanhada do seu diretor.

${ }^{2}$ Esta escolha justifica-se em função de o centro de pesquisa CfLaT (https://www.ncl.ac.uk/cflat/) ser conhecido pelas suas contribuições científicas na área da arquitetura escolar e a sua inserção nos conceitos atuais educacionais, bem como pelo desenvolvimento de métodos visuais criativos de APO envolvendo participantes. 
Quadro 2 - Instrumentos adotados - adaptado de Ono et al. (2018)

\begin{tabular}{|c|c|c|c|c|}
\hline & Instrumento & Participantes & Aspectos avaliados & Escola \\
\hline \multirow{2}{*}{ 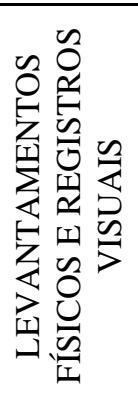 } & 1. Walkthrough & $\begin{array}{l}\text { Especialista+membro da } \\
\text { escola }\end{array}$ & $\begin{array}{l}\text { Reconhecimento de espaços } \\
\text { e usos, observações } \\
\text { relacionadas aos PPs e } \\
\text { informações técnicas da } \\
\text { escola. }\end{array}$ & $\begin{array}{l}\text { E1 } \\
\text { E2 }\end{array}$ \\
\hline & 2. Análise de PPs & Especialista & $\begin{array}{l}\text { Averiguação e anotações da } \\
\text { existência de PPs. }\end{array}$ & E2 \\
\hline \multirow{3}{*}{ 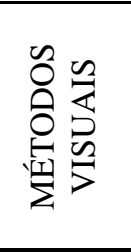 } & 3. Diamond ranking* & Usuários (alunos) & $\begin{array}{l}\text { Atividade para análise de } \\
\text { imagens. }\end{array}$ & E1 \\
\hline & $\begin{array}{l}\text { 4. Análise de plantas } \\
-2 \text { níveis* }\end{array}$ & Usuários (alunos) & $\begin{array}{l}\text { Atividade para análise do } \\
\text { edifício escolar em questão. }\end{array}$ & E1 \\
\hline & $\begin{array}{l}\text { 5. Análise de plantas } \\
-6 \text { níveis* }\end{array}$ & $\begin{array}{l}\text { Usuários (alunos e } \\
\text { professores) }\end{array}$ & $\begin{array}{l}\text { Atividade para análise do } \\
\text { edifício escolar em questão. }\end{array}$ & E2 \\
\hline
\end{tabular}

Nota: *recomenda-se a interação do especialista sobre as escolhas, de modo a criar maior engajamento, mas sem direcionar respostas.

\section{Métodos visuais}

Os métodos visuais aplicados na pesquisa se enquadram nos instrumentos descritos por Ono et al. (2018) para gerenciar e estimular grupos focais. Estes são atividades coletivas com objetivo de estimular discussões de um tema, e visando à apresentação das opiniões, convergentes ou divergentes, dos participantes, analisando os motivos e os destaques dessas perspectivas. Instrumentos visuais foram divulgados na década de 1990 por Sanoff (1991), que apresenta vários métodos para a compreensão do comportamento humano no ambiente construído e para levantamentos eficazes de percepções sobre estes espaços. Outras importantes contribuições nesse sentido para a APO, e para processos participativos, foram também desenvolvidos no Brasil. Representações de conceitos de forma gráfica para avaliações de ambientes e para a condução de grupos focais podem ser encontrados em Günther, Elali e Pinheiro (2008), Granja et al. (2009), Rheingantz et al. (2009), Azevedo (2012), Elali e Veloso (2006), Deliberador (2016), Villa , Saramago e Garcia(2016), entre outros.

Os métodos visuais, segundo Prosser (2007), trabalham com produção, organização e interpretação de imagens. Clark et al. (2013), do grupo CfLaT, e Harper (2002) defendem a aplicação de atividades com imagens por ser um exercício lúdico que tende a aumentar a qualidade dos resultados ao encorajar o envolvimento daqueles participantes mais relutantes com exercícios de leitura e escrita, ou inibidos de apresentarem suas opiniões de outra maneira. Consequentemente, é possível estabelecer mais conexões, tanto entre os usuários participantes, quanto sobre as ideias discutidas, auxiliando na compreensão de seus pontos de vista e necessidades.

O registro de observações pelos usuários proporciona um resultado prévio, que posteriormente necessita de interpretações dos especialistas. Para Woolneret al. (2010), esses métodos se mostram apropriados para a investigação da experiência dos usuários em um ambiente escolar, mas Kim, Cha e Kim (2016) veem essa aplicação ainda pouco explorada. Assim, considera-se que uma pesquisa com métodos visuais se mostra aplicável tanto em um processo participativo de projeto, quanto durante a fase de APO escolar, para compreender quem são os usuários, suas reações e expectativas de projeto ou espaços que frequentam. Recomenda-se que os métodos sejam aplicados em um mesmo dia para manter a coesão do grupo na sua interpretação das imagens e dos espaços, como realizado neste estudo. $\mathrm{Na}$ E1 foram aplicados os instrumentos 3 e 4 (Tabela 1), enquanto na E2, o instrumento 5.

\section{Diamond ranking}

Uma das maneiras de se trabalhar com métodos visuais é pelo uso da ferramenta de diamond ranking (Figura 1). Ao ranquear itens, é exigido dos participantes que deixem claro os motivos que os levaram aos posicionamentos determinados, organizando as informações presentes em suas mentes. Dessa maneira é 
possível compreender o nível de importância/uso/percepção de cada elemento das imagens. Atividades realizadas dessa maneira são tradicionalmente utilizadas em escolas, com alunos; entretanto, Clark et al. (2013) apontam que esse método pode ser aplicado em uma variedade de panoramas, com participantes e objetivos diferentes.

Aos participantes são entregues nove imagens representando uma variedade de perspectivas. No caso dessa pesquisa, a escolha das imagens foi feita com base nos PPs. A atividade do diamond ranking normalmente ocorre em pares ou trios, e estes precisam definir a alocação de cada imagem como indicado na Figura 1 pelo seu nível de significância. As imagens de um mesmo nível têm igual valor, mas são mais bem avaliadas que as de nível inferior, e mais mal avaliadas que as de nível superior a elas. A escala semântica pode ser modificada para, por exemplo, "interessante", "importante" ou "melhor".

O grupo de pesquisa CfLaT possui experiência com essa atividade e acredita que ter que lidar com as imagens, recortando-as (quando há tempo hábil), observando-as, categorizando-as e discutindo sobre as escolhas, é importante para envolver os participantes. As imagens se tornam guias para as discussões desenvolvidas, também funcionando como abertura de possibilidades de projeto e estímulo à memória. Para Clark et al. (2013), durante o diamond ranking são abertas opiniões de forma fluida e há expansão da imaginação dos participantes.

\section{Análise de plantas}

Enquanto o método de diamond ranking indica diferentes propostas arquitetônicas, a análise de plantas direciona a discussão para o objeto de estudo. Esse instrumento auxilia o levantamento de dados sobre a funcionalidade e uso de ambientes e, por consequência, fornece informações que podem facilitar a criação de um programa arquitetônico para construções novas ou reforma de escolas. Os participantes da atividade são usuários desses espaços e o conhecem pela sua vivência.

As análises são realizadas por meio de classificação da eficácia dos espaços, por cores. Para facilitar a compreensão da representação da escola (desenho técnico), recomenda-se a disposição das plantas de todos os pavimentos em página única. Recomenda-se também que as atividades sejam realizadas de preferência em duplas, trios ou no máximo grupos de quatro pessoas. A participação individual depende da disponibilidade e do número de participantes.

A Figura 2 mostra um esquema com duas possibilidades de classificação dos espaços. A primeira é a classificação em dois níveis: eficaz e não eficaz (verde e vermelho, respectivamente). Nessa avaliação, os participantes recebem um número não limitado de adesivos e é solicitado o destaque de tantos ambientes quanto considerados necessários, anotando o máximo de observações possíveis.

\section{Figura 1 - Organização do diamond ranking}

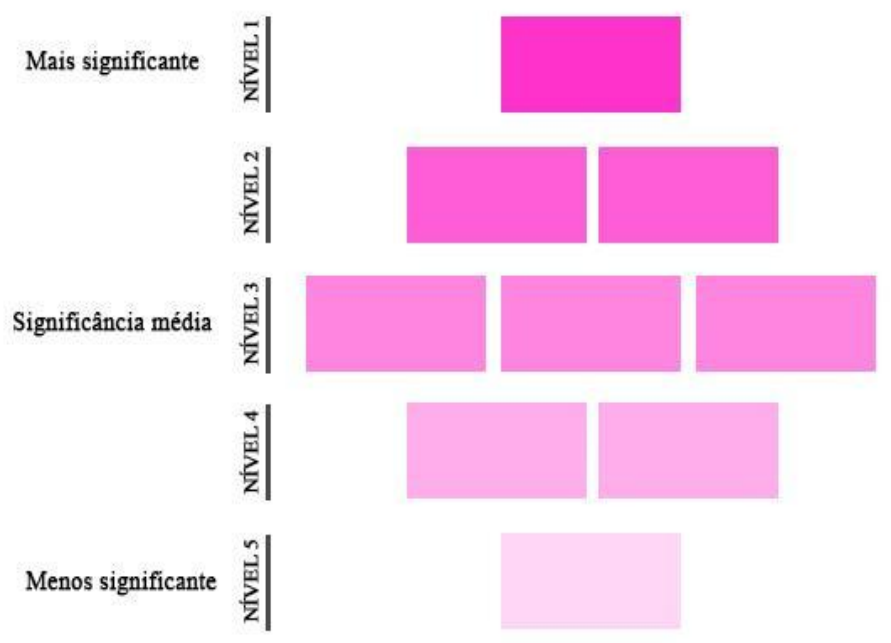

Fonte: adaptado de Clark et al. (2013). 
Figura 2 - Modelos esquemáticos para análise de plantas

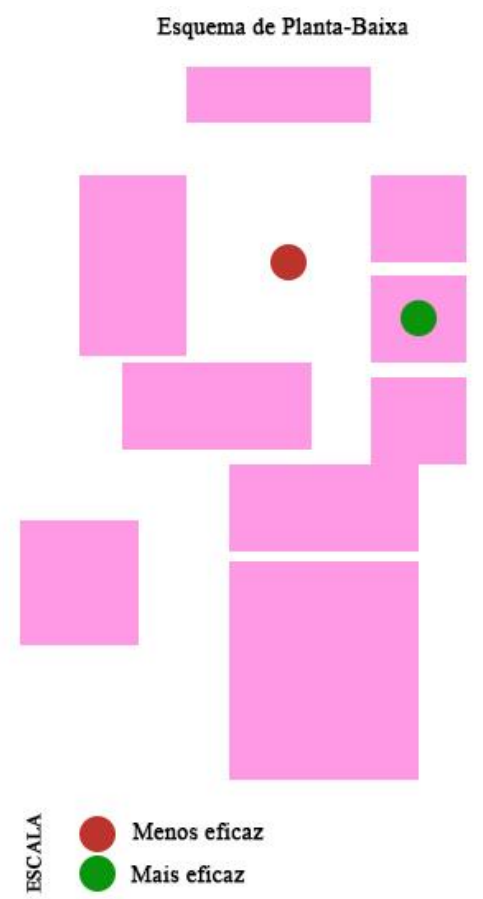

(a) Análise em 2 níveis

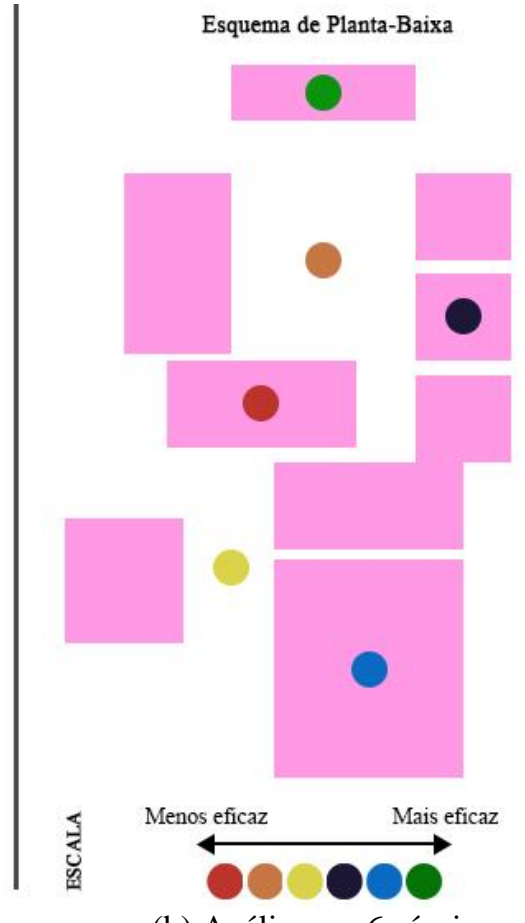

(b) Análise em 6 níveis

A segunda abordagem é o uso de uma escala ampliada, com caracterização mais detalhada, em seis níveis.Essa ampliação na avaliação de eficácia dos ambientes permite analisar nuances da funcionalidade dos espaços. Assim, um ambiente avaliado em verde (eficaz) é percebido como positivo. Na medida em que esses pontos positivos têm menos impacto, os espaços são avaliados em azul e, posteriormente, roxo. Quando os pontos negativos do ambiente ultrapassam os positivos, estes passam a ser avaliados em amarelo e laranja, até alcançar a maior avaliação negativa, em vermelho (não eficaz). Nessa atividade é entregue um grupo de adesivos de seis cores para cada participante e essa limitação ocorre devido ao número de pontos destacados, seis por pessoa.

\section{Resultados}

Os resultados coletados tiveram origem na aplicação dos instrumentos listados noQuadro 2. O walkthrough permitiu a familiarização com os ambientes em ambos os casos. Na E1 também foram aplicados o diamond ranking e análise de plantas (2 níveis), e na E2 foram aplicadas a análise de PPs e as análise de plantas (6 níveis). Os resultados são organizados por escola. As atividades com plantas foram realizadas com a representação gráfica em desenho técnico. Neste artigo, porém, de modo a aumentar a clareza das informações explicitadas, foram feitos esquemas (diagramas) dessas plantas.

\section{Escola 1 (E1)}

A E1, de três pavimentos, atende aproximadamente 850 alunos e se divide em departamentos (Figura 3). O sistema construtivo é alvenaria de tijolo maciço, com painéis de esquadrias metálicas nas fachadas. A cobertura do edifício também é metálica. A escola, construída na década de 1960, foi reformada em 2005 , quando se buscou ampliar a área construída para atender mais alunos. Essa reforma introduziu novas construções entre volumes existentes da escola. Houve foco na melhoria da funcionalidade de ambientes (em especial dos laboratórios de ciência, quadra de esportes e refeitório) e redução de ruídos de impacto com o uso de carpetes nos corredores. Outro objetivo da reforma foi oferecer espaços para atividades comunitárias (academia e ginásio). Questões de segurança também foram melhoradas para delimitar o terreno e câmeras de vigilância foram instaladas no campus. 
Figura 3 - Diagrama das plantas da E1

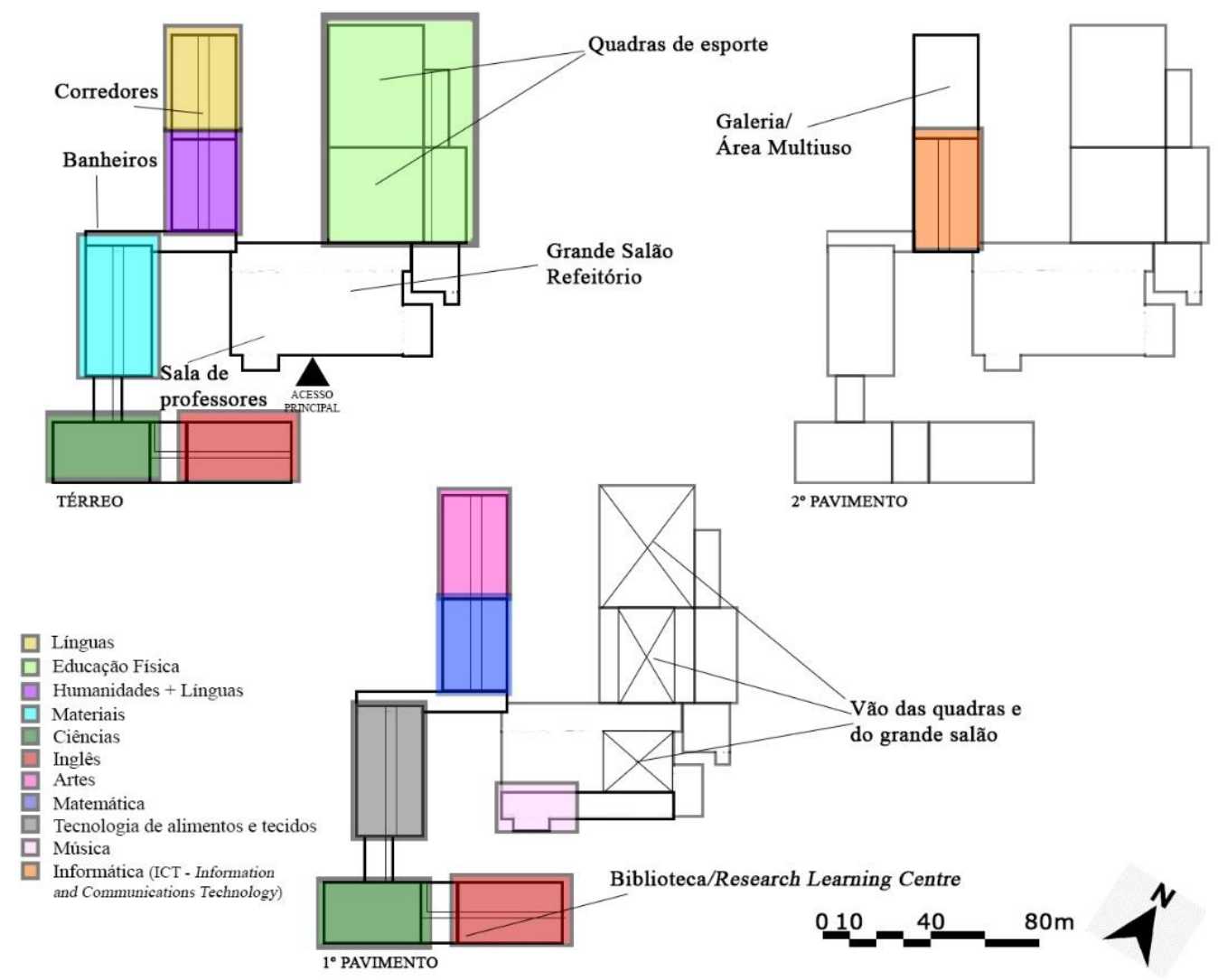

Durante o walkthrough, realizado em 2017 e com duração aproximada de 2h, observou-se a existência de ambientes diversificados pela demanda curricular, mas que ainda utilizam poucos dos PPs aqui descritos. Seis PPs foram apontados como presentes:

(a) espaços para educação física (uma atividade forte da escola, que funciona como um centro de treinamento de professores dessa área);

(b) campfire space (existência de um local de apresentações e palestras);

(c) assinatura local (o que se conecta aos valores da escola com relação ao seu edifício original e à expressão da pedagogia utilizada em sua composição arquitetônica);

(d) conexão com a comunidade; e

(e) recursos de aprendizado compartilhados e biblioteca (com conexão visual e transparência na área multiuso e recursos variados tanto nessa área quanto na biblioteca - learning resource centre, LRC) e proteção e segurança.

Outros 15 parâmetros existem parcialmente, não atendendo a todos os aspectos conceituais de suas respectivas descrições. Dentre eles estão:

(a) transparência (vista apenas na área multiuso, na conexão do refeitório com o corredor e em uma área do LRC); e

(b) tecnologia distribuída (mas a distribuição geral ainda é limitada) e áreas de exposição de trabalho (que a escola possui, mas são pouco utilizadas).

Enquanto as duas primeiras visitas foram de reconhecimento do local (com alunos, observando a ocupação, e sem alunos, para registros visuais), na terceira visita foram coletados dados baseadas nos métodos visuais. As atividades foram realizadas com a participação de 12 estudantes do $7^{\circ}$ e $9^{\circ}$ ano escolar, divididos em duplas. 


\section{Diamond ranking}

No diamond ranking nove imagens foram apresentadas para os alunos (Figura 4). Para a escolha foi dada prioridade para imagens com presença humana, ou com evidências de ocupação, de modo que as observações dos participantes fossem tanto pelas características físicas quanto pelo uso dos espaços. Recomenda-se que a definição das imagens seja feita observando ambientes positivos, evitando espaços claramente não recomendáveis (espaços deteriorados ou com iluminação inadequada, entre outros).

Características baseadas nos PPs também direcionaram a seleção de imagens. Trabalhou-se de modo especial com os parâmetros salas de aula, ambientes de ensino e pequenas comunidades de aprendizagem; espaço individual para armazenamento; transparência; mobiliários confortáveis; espaços flexíveis; watering hole space; cave space; projeto para múltiplas inteligências. Focou-se também em variações de cores, acabamento e forma dos ambientes. Na aplicação do método solicitou-se aos alunos que fizessem comentários de suas escolhas para auxiliar na compreensão do posicionamento das imagens.

A Figura 5 apresenta o resultado de uma dupla de alunos. Na atividade foram gerados 6 diagramas que foram compilados na Figura 6, a qual apresenta a frequência de ranqueamento das imagens em cada nível: topo, alto, meio, baixo, inferior. Os alunos fizeram comentários sobre cores/acabamento dos espaços, iluminação, conforto, conexões por transparência, tecnologia, trabalho em grupo, estudo individual e espaço para armazenamento. Esses aspectos fazem parte das descrições dos PPs, direta ou indiretamente, o que indica sua importância no projeto arquitetônico.

Figura 4 - Imagens para diamond ranking

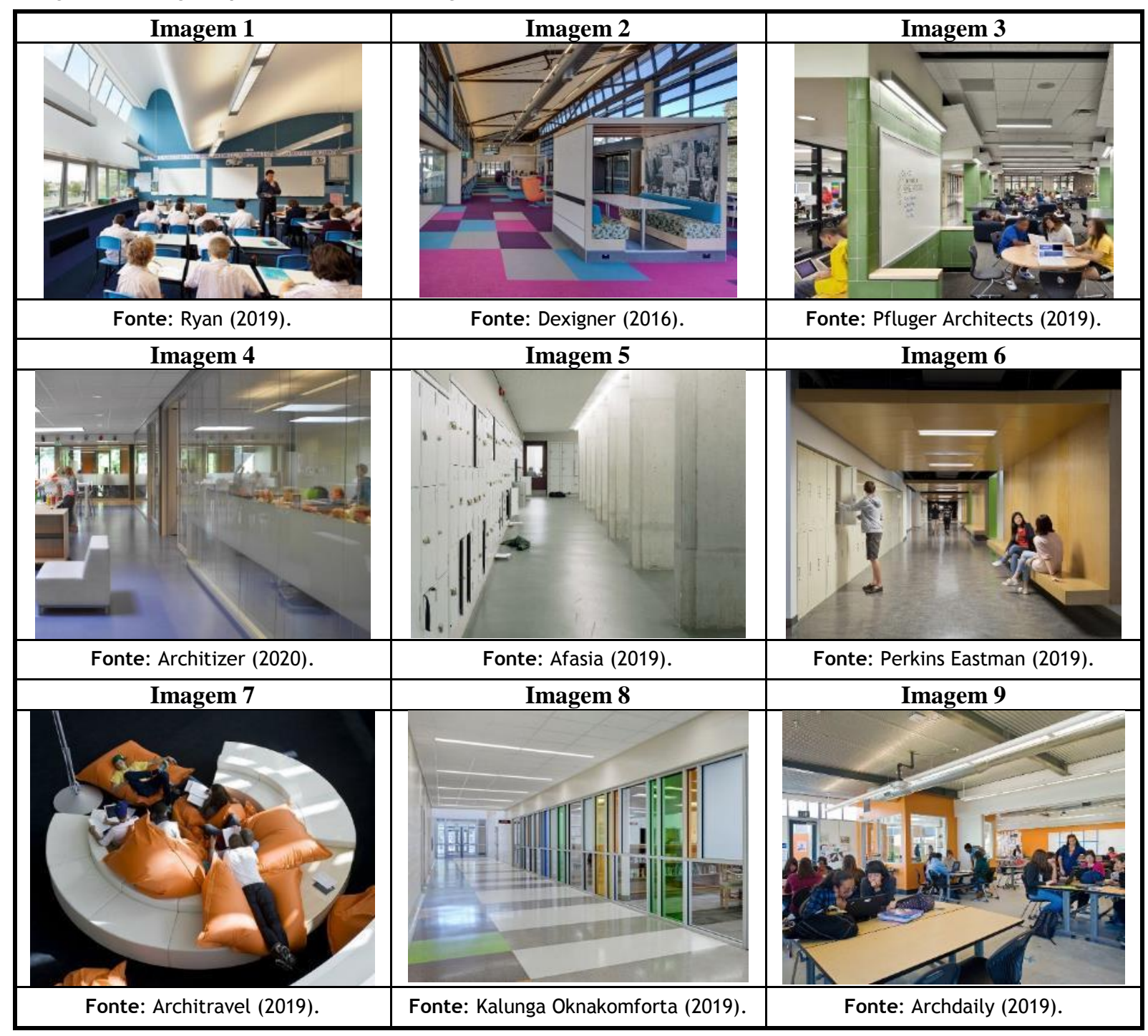


Figura 5 - Diamond ranking de uma dupla - E1 - demonstrativo do uso do método

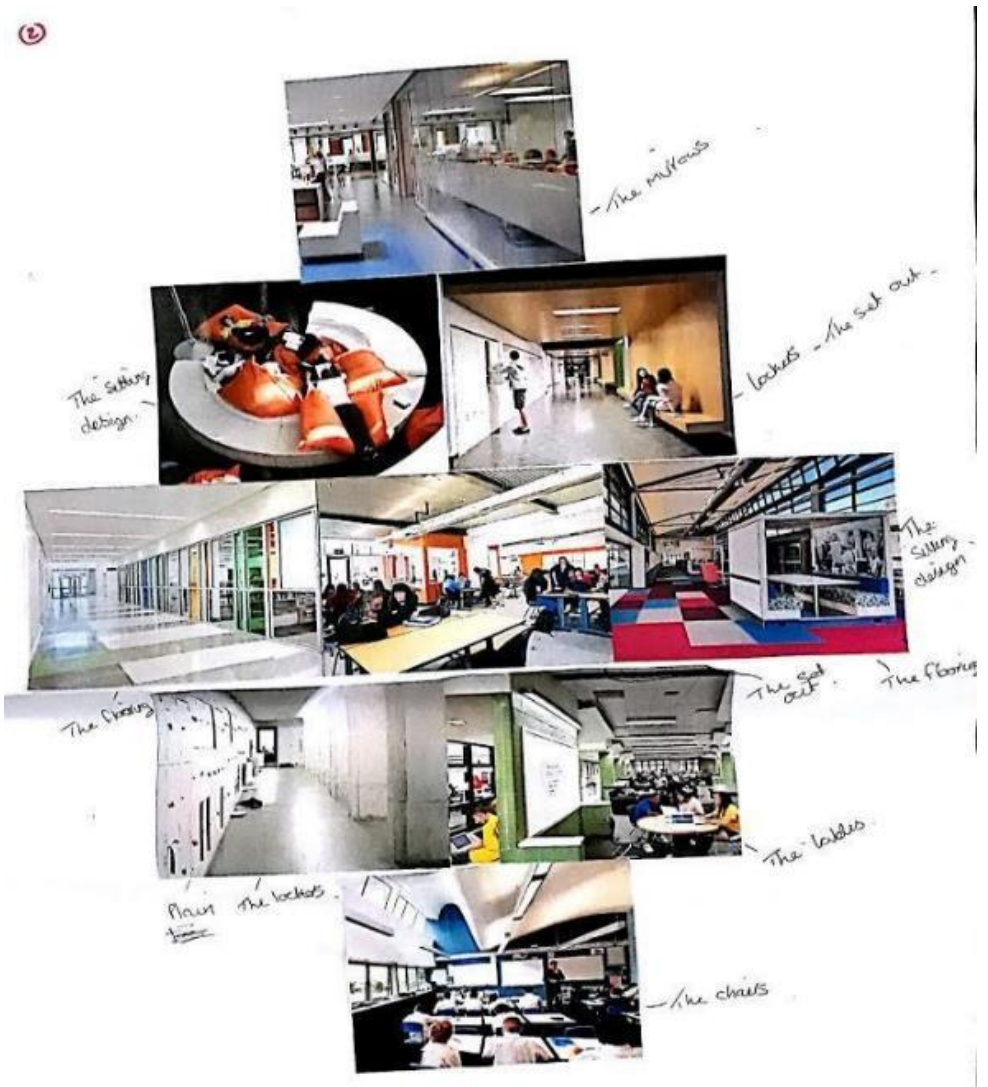

Fonte: arquivo das autoras (2017).

Figura 6 - Resultados dos diamond rankings

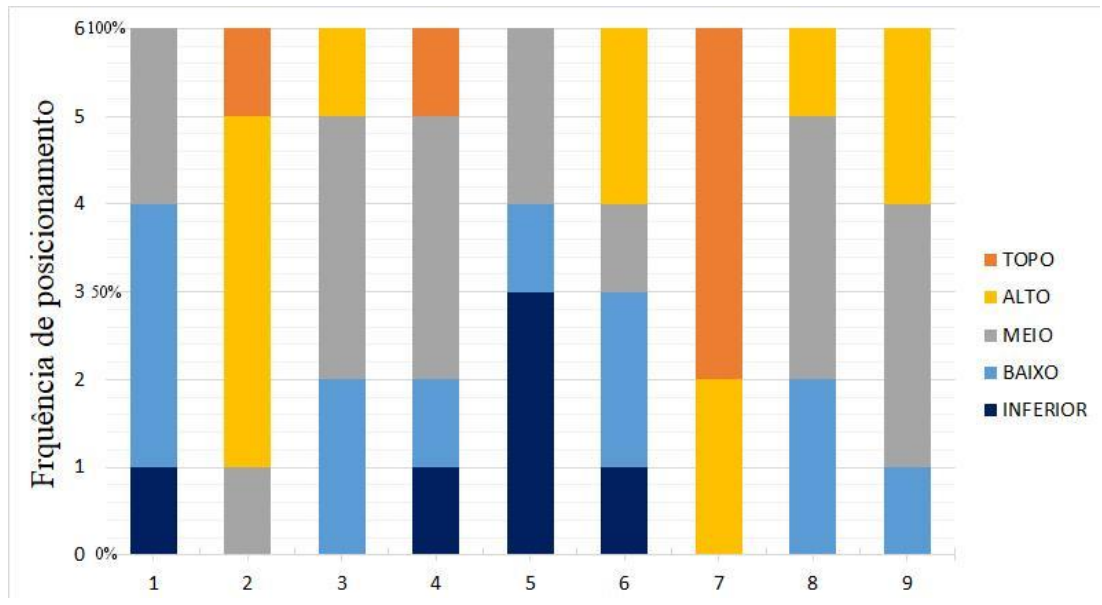

A imagem 5 da Figura 4 foi mais frequentemente posicionada em "inferior", mesmo apresentando característica valorizada pelos alunos: espaço para armazenamento. Foram feitas observações de que o espaço não é interessante pelo tipo de acabamento e falta de cores. A imagem 7 foi a que mais apareceu no "topo" com mobiliário confortável e para descanso (elemento que pode ser mais bem avaliado de modo a compreender o uso de espaços informais). A imagem 2, mais vezes posicionada na seção "alta", foi classificada como clara, vibrante, com cores consideradas boas (destaca-se o piso) e com locais para se sentar confortavelmente, inclusive para se fazer tarefas/estudar. 


\section{Análise de plantas - 2 níveis}

A atividade com plantas foi compilada em arquivo único e foi feito esquema simplificado para apresentação (Figura 7). É possível verificar o posicionamento dos pontos relativos aos espaços eficazes (em verde) e não eficazes (em vermelho). Nesse momento os PPs são base para compreender características físicas da escola e auxiliam a definir aspectos considerados positivos para serem acrescentados em possíveis projetos futuros (tanto de reforma da escola visitada, quanto para novos projetos).

Na Figura 7 destacam-se: os corredores, considerados estreitos para períodos de maior fluxo, e os banheiros, apontados como espaços de tamanho e aspecto inadequado. A maioria das classificações na quadra de esportes apontou que essa área é eficaz. O grande salão, importante foco na reforma, foi pouco analisado, mas recebeu um marcador vermelho. A galeria, com características que se aproximam aos PPs, foi avaliada majoritariamente como eficaz em função do seu tamanho e pelos ambientes oferecidos: salão (espaço flexível), e salas com transparência e usos diversos. O LRC foi classificado, em geral, como eficaz. Não há observações específicas com relação às salas de aula.

\section{Escola 2 (E2)}

A E2, de três pavimentos, foi construída em 2009 e atende quase 1.000 alunos no EFII. O novo edifício foi construído em alvenaria rebocada e pintada, com grandes esquadrias metálicas e cobertura de telha metálica. Antes de sua construção, a escola ocupava outro edifício, no mesmo terreno, que foi demolido. O novo prédio tinha como um dos objetivos a expansão para inclusão de maior número de alunos e ampliação da faixa etária, incluindo o ensino médio.

Figura 7 - Análise das plantas da E1 pelos alunos - 2 níveis

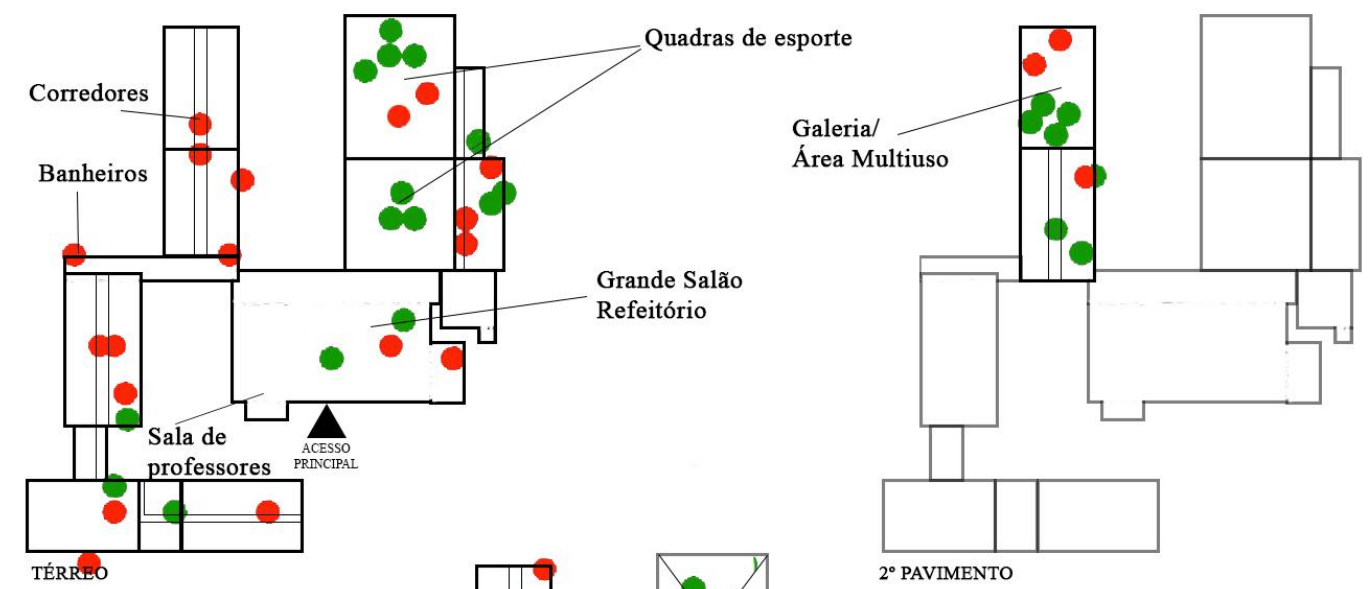

Menos eficaz Mais eficaz

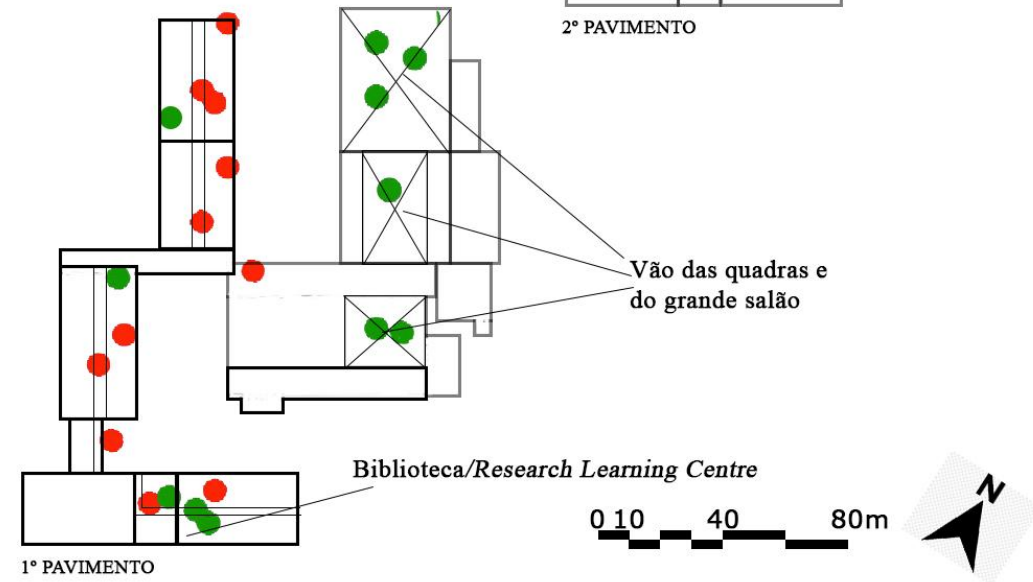


O projeto da escola ouviu os professores e a diretoria, mas também os alunos. Dentre os pontos de destaque estão:

(a) implantação com uma das fachadas voltadas ao mar;

(b) varandas permitindo acesso externo dos ambientes de ensino;

(c) uso de material específico nas janelas que permitisse iluminação natural sem aquecimento solar excessivo;

(d) zoneamento por departamento;

(e) salas de informática e biblioteca conectados visualmente a um átrio de entrada;

(f) salas de suporte para professores (além da sala dos professores);

(g) armários individuais para alunos nos corredores (sem comprometer a largura destes);

(h) aumento na largura das escadas;

(i) carpetes nos corredores e escadas para controle de ruídos;

(j) salão para assembleias com divisória móvel para quadra de esportes;

(k) auditório com divisória móvel para o refeitório;

(l) recepção exclusiva para utilização do edifício pela comunidade; e

(m) academia e estúdio de dança.

A escola é apresentada na Figura 8.

\section{Parâmetros de projeto}

Durante o walkthrough foram observados PPs. O percurso foi realizado em 2017 e teve duração aproximada de $2 \mathrm{~h}$, quando também foi possível tirar fotos. Anotações gerais foram feitas e, posteriormente, foram sistematizadas na tabela da Figura 9. Essa figura apresenta as observações sobre cada parâmetro, indicando aqueles encontrados e como a escola foi projetada, importante base de informações da APO. Na Figura 10 pode-se notar que há presença completa de 9 PPs, 16 parcialmente existentes e 4 não existentes. A soma dos existentes e parcialmente existentes está em torno de $90 \%$ dos PPs recomendados para uma arquitetura escolar de qualidade.

Um dos destaques dessa análise é o PP\#1 (ambientes de ensino/aprendizagem). Observou-se que na E2 existe diversidade de ambientes para abrigar variedade curricular, mas esses espaços são pouco flexíveis. Essa ressalva também foi feita durante o walkthrough, indicando que 10 anos após a construção da escola as necessidades modificaram-se e ambientes adaptáveis se tornaram novos requisitos.

Dentre os parâmetros considerados de maior importância estão os 15, 16 e 17: campfire, wateringhole e cave space. A presença dos três PPs está relacionada ao reconhecimento da importância da multiplicidade de atividades pedagógicas, sejam elas em grupos grandes, pequenos ou individualmente. O PP\#15 foi considerado como existente, em função do auditório (associado ao ambiente do refeitório) e o salão principal (associado ao ambiente de educação física). O PP\#16 foi observado pela forma como a biblioteca foi posicionada na escola e como ela é ocupada, contudo não se encontrou esse parâmetro distribuído em outros espaços. O PP\#17, que tem como características nichos para atividades individuais, não foi encontrado. 
Figura 8 - Planta da escola E2 com divisão por departamento

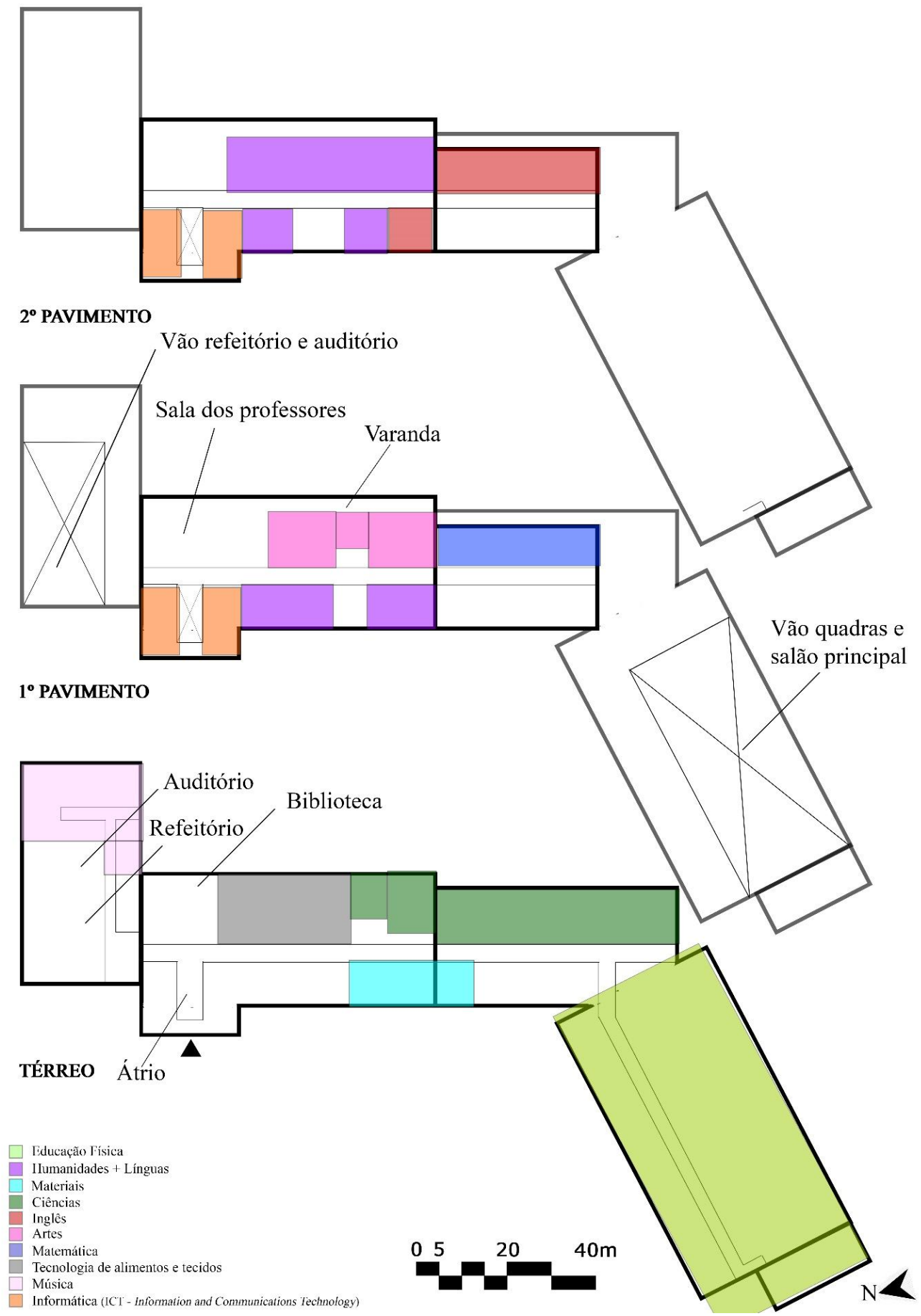


Figura 9 - Análise de PPs - E2

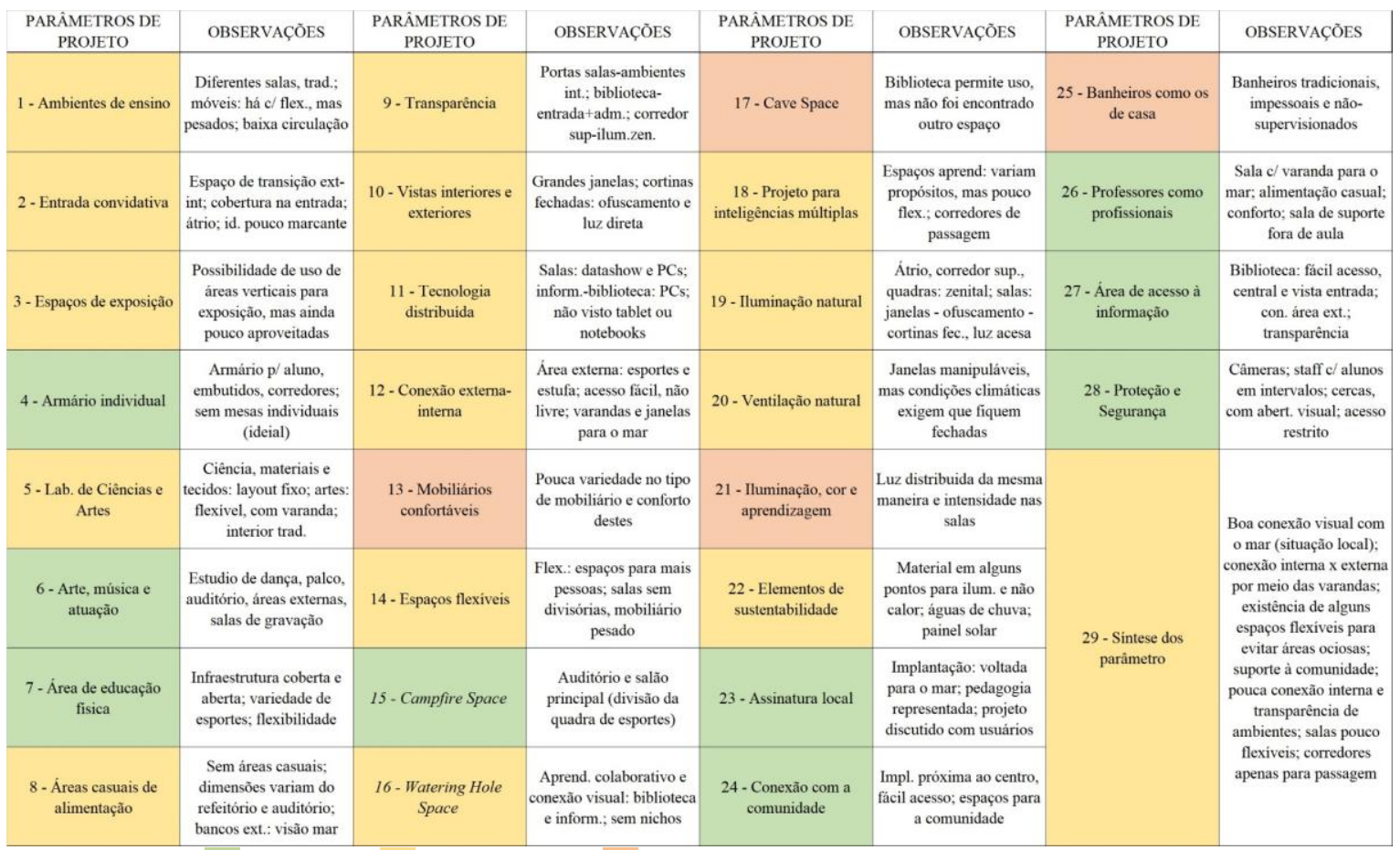

Nota: Legenda:

Existente

\section{Existe parcial}

\section{Não existe}

Figura 10 - Existência de PPs - E2

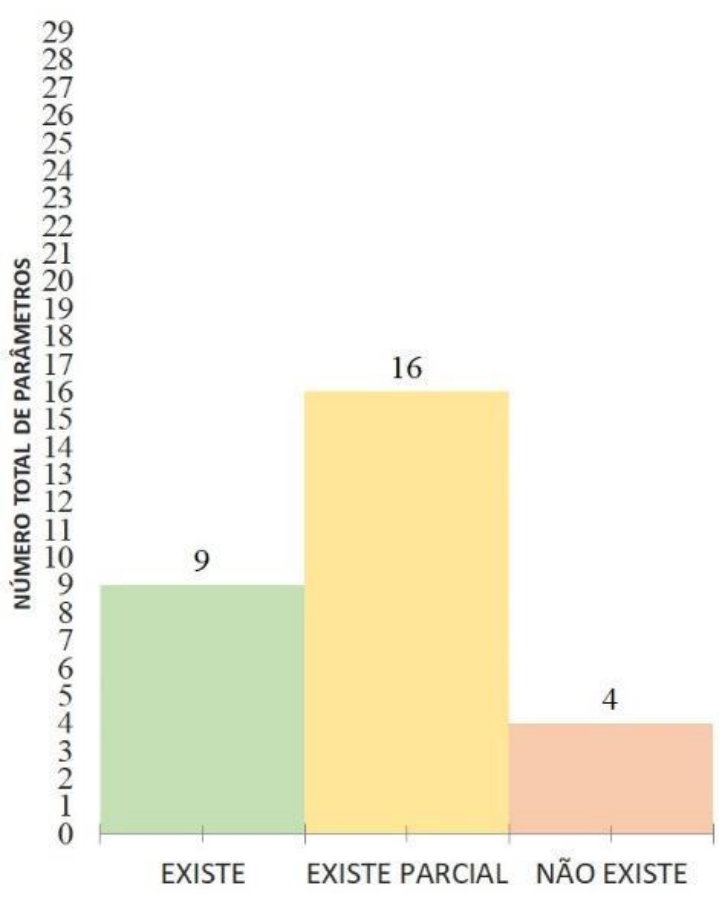

\section{Análise de plantas - 6 níveis}

A atividade com plantas divide-se em duas: análise dos alunos e dos professores. As Figuras 11 e 15 apresentam os resultados, seguidas, respectivamente, das Figuras 12, 13 e 14 e Figuras 16 e 17, que contêm detalhes das observações sobre os ambientes. Participaram 15 alunos, divididos em três grupos de quatro integrantes e um trio, e ainda quatro professores avaliando individualmente devido à disponibilidade deles. A atividade com alunos foi realizada com a presença da especialista, enquanto a atividade com professores 
foi realizada sem esta. Cada pessoa recebeu seis adesivos (vermelho, laranja, amarelo, roxo, azul e verde), representando a variação de eficácia a ser avaliada e foi solicitada a anotação de comentários nas escolhas.

Figura 11 - Análise das plantas da E2 pelos alunos - 6 níveis

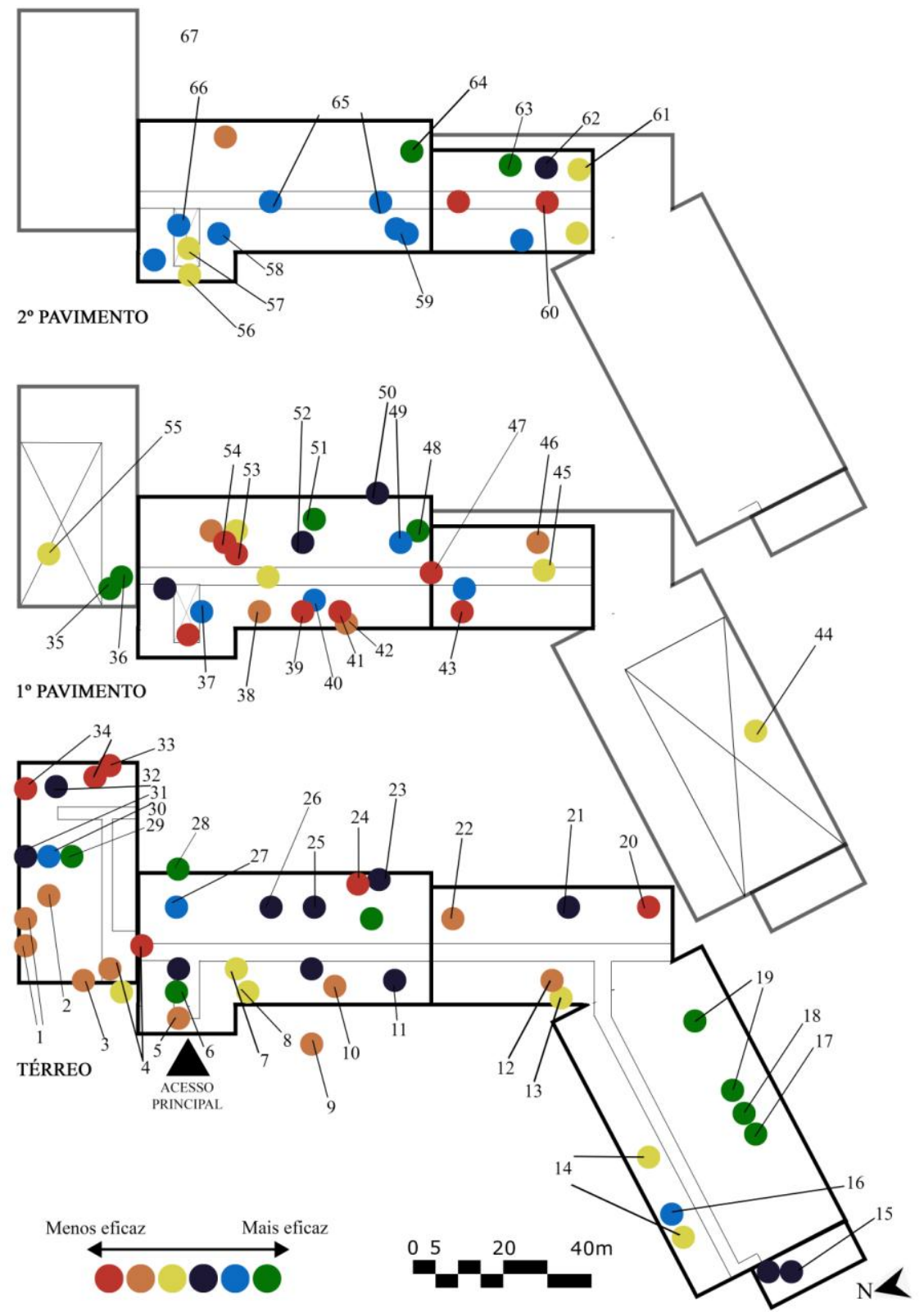


Figura 12 - Observações numeradas de acordo com a Figura 11 - comentários 1 a 24

\begin{tabular}{|c|c|c|c|}
\hline Número & Nível & Local & Comentários \\
\hline 1 & & Refeitório & Pequeno \\
\hline 2 & & Refeitório & Refeitório precisa de mais espaço \\
\hline 3 & & Banheiro & Banheiro muito pequeno \\
\hline 4 & & $\begin{array}{l}\text { Acesso ao } \\
\text { refeitório }\end{array}$ & $\begin{array}{l}\text { Ponto mais perigoso na escola / tumultos } \\
\text { / bullying. Precisa de controle de multidões }\end{array}$ \\
\hline 5 & & Hall de entrada & Falta segurança na entrada \\
\hline 6 & & Hall de entrada & Bom uso para espaços pequenos \\
\hline 7 & & Sala de reflexão & $\begin{array}{l}\text { Sala para alunos em atividades individuais } \\
\text { muito quente e não há espaço, } \\
\text { especialmente se a pessoa estiver doente }\end{array}$ \\
\hline 8 & & Sala do silêncio & Precisa demais espaço \\
\hline 9 & & $\begin{array}{l}\text { Ponto para filas } \\
\text { para refeições }\end{array}$ & Barras e cordas para ajudar a controlar filas \\
\hline 10 & & Escadas & $\begin{array}{l}\text { Muito pequeno / abarrotado Movimentação } \\
\text { limitada }\end{array}$ \\
\hline 11 & & Sala de Materiais & Sala fria \\
\hline 12 & & Escadas & Escada precisa ser mais larga \\
\hline 13 & & Escadas & Não há espaço suficiente na escada \\
\hline 14 & & Vestiários & Muito apertado / falta espaço no vestiário \\
\hline 15 & & Academia & Boas instalações de academia \\
\hline 16 & & Vestiários & $\begin{array}{l}\text { Embora tenha um bom espaço para } \\
\text { vestiário, são necessários mais chuveiros }\end{array}$ \\
\hline 17 & & Quadra & Eficaz para tudo - esportes / exames \\
\hline 18 & & Quadra & Quadra espaçosa \\
\hline 19 & & Quadra & Salão espaçoso / muito espaço para esportes \\
\hline 20 & & $\begin{array}{l}\text { Laboratório de } \\
\text { Ciências } 7\end{array}$ & Mau-cheiro \\
\hline 21 & & $\begin{array}{l}\text { Laboratório de } \\
\text { Ciências } 5\end{array}$ & Espaçoso / bom espaço para as práticas \\
\hline 22 & & $\begin{array}{l}\text { Laboratório de } \\
\text { Ciências } 3\end{array}$ & Ruído das salas adjacentes \\
\hline 23 & & $\begin{array}{l}\text { Laboratórios de } \\
\text { Ciências } 1 \text { e } 2\end{array}$ & Essas salas de ciências são muito apertadas \\
\hline 24 & & $\begin{array}{l}\text { Laboratório de } \\
\text { Ciências } 1\end{array}$ & Muito pequeno \\
\hline 25 & & $\begin{array}{l}\text { Sala de } \\
\text { Tecnologia de } \\
\text { Alimentos }\end{array}$ & Muito espaço para trabalho \\
\hline
\end{tabular}


Figura 13 - Observações numeradas de acordo com a Figura 11 - comentários 25 a 48

\begin{tabular}{|c|c|c|c|}
\hline Número & Nível & Local & Comentários \\
\hline 26 & & $\begin{array}{l}\text { Sala de } \\
\text { Tecnologia de } \\
\text { Alimentos e } \\
\text { Tecidos }\end{array}$ & Bem equipado para atividades diversas \\
\hline 27 & & Biblioteca & Mais computadores são necessários \\
\hline 28 & & Biblioteca & Boa conexão com o espaço externo \\
\hline 29 & & Auditório & Grande, comporta muitas pessoas \\
\hline 30 & & Auditório & Bom tamanho o auditório \\
\hline 31 & & Auditório & Assembleias importantes \\
\hline 32 & & Sala de Música 2 & Espaçoso e bem isolado acusticamente \\
\hline 33 & & Sala de Música 1 & Sala de música ineficiente \\
\hline 34 & & $\begin{array}{l}\text { Sala de Música } 1 \\
\text { e } 2\end{array}$ & $\begin{array}{l}\text { Muito iluminado, janelas muito grandes e्र com } \\
\text { cortinas fechadas, muito escuro - sala música }\end{array}$ \\
\hline 35 & & $\begin{array}{l}\text { Sala de } \\
\text { Conferência }\end{array}$ & Faz sentir especial - sala reuniões \\
\hline 36 & & $\begin{array}{l}\text { Sala de } \\
\text { Conferência }\end{array}$ & Bom espaço/ cadeiras confortáveis \\
\hline 37 & & $\begin{array}{l}\text { Sala de } \\
\text { Informática } 21\end{array}$ & Boa vista/transparência - ICT \\
\hline 38 & & $\begin{array}{l}\text { Sala de } \\
\text { Humanidades } 23\end{array}$ & Claustrofóbica \\
\hline 39 & & $\begin{array}{l}\text { Sala de } \\
\text { Humanidades } 24\end{array}$ & Não inclusiva \\
\hline 40 & & $\begin{array}{l}\text { Sala de } \\
\text { Humanidades } 24\end{array}$ & $\begin{array}{l}\text { Bom layout. Gosto do nicho no corredor, pois } \\
\text { dá mais espaço }\end{array}$ \\
\hline 41 & & Escadas & Muito estreito para saída de emergência \\
\hline 42 & & Escadas & Escadas ficam apertadas \\
\hline 43 & & Sala de Estudos & Grandes janelas - Sala de estudos \\
\hline 44 & & Quadra44 & $\begin{array}{l}\text { Vão poderia ser usado para novas salas ou } \\
\text { estufa }\end{array}$ \\
\hline 45 & & Corredor & Precisa ser mais largo \\
\hline 46 & & $\begin{array}{l}\text { Sala de } \\
\text { Matemática } 32\end{array}$ & $\begin{array}{l}\text { Iluminada, janelas de bom tamanho bom } \\
\text { layout }\end{array}$ \\
\hline 47 & & Corredor & Corredores congestionados \\
\hline 48 & & Sala de Artes 24 & $\begin{array}{l}\text { Acesso à varanda / grande e iluminada / } \\
\text { acesso a outras salas }\end{array}$ \\
\hline
\end{tabular}


Figura 14 - Observações numeradas de acordo com a Figura 11 - comentários 49 a 67

\begin{tabular}{|c|c|c|c|}
\hline Número & Nível & Local & Comentários \\
\hline 49 & & Sala de Artes 24 & Bom espaço \\
\hline 50 & & Varanda & Ar fresco / poderia ser mais acessível \\
\hline 51 & & Sala de Artes 22 & Bom espaço. Bem mobiliado e equipado \\
\hline 52 & & Sala de Artes 22 & Muito grande \\
\hline 53 & & Sala de Estudos & Muito pequena e não pode acessar a varanda \\
\hline 54 & & Sala de Estudos & Muito grande \\
\hline 55 & & Refeitório & Vão pode ser usado como salas / hall \\
\hline 56 & & $\begin{array}{l}\text { Suporte } \\
\text { Informática }\end{array}$ & Frio \\
\hline 57 & & Átrio & $\begin{array}{l}\text { Muito alto / alunos têm medo. Desperdiça } \\
\text { energia }\end{array}$ \\
\hline 58 & & $\begin{array}{l}\text { Sala de } \\
\text { Informática/ } \\
\text { Negócios }\end{array}$ & Computadores úteis / ajudam na educação \\
\hline 59 & & $\begin{array}{l}\text { Sala de } \\
\text { Humanidades } 6\end{array}$ & Ruído mínimo \\
\hline 60 & & Corredor & Corredores congestionados \\
\hline 61 & & Sala de Inglês 6 & $\begin{array}{l}\text { Sala desnecessária. Parede treme e faz } \\
\text { barulho quando atingida pelo vento }\end{array}$ \\
\hline 62 & & Sala de Inglês 5 & Iluminado, cheio de instalações. Bom layout \\
\hline 63 & & Sala de Inglês 4 & Grandes janelas \\
\hline 64 & & Sala de Inglês 2 & $\begin{array}{l}\text { Ótima sala / temperatura certa / boa vista / } \\
\text { não consigo ouvir as pessoas ao lado }\end{array}$ \\
\hline 65 & & Corredor & Corredor iluminado devido ao teto \\
\hline 66 & & $\begin{array}{l}\text { Átrio e } \\
\text { Laboratórios de } \\
\text { Informática }\end{array}$ & $\begin{array}{l}\text { Instalação de ICT e varanda são boas devido } \\
\text { às janelas }\end{array}$ \\
\hline 67 & - & Edifício & $\begin{array}{l}\text { Em nossa opinião, o piso superior é o melhor } \\
\text { e o térreo é o pior. Temos um enorme } \\
\text { problema com paredes finas - todas as salas } \\
\text { precisam de paredes mais espessas }\end{array}$ \\
\hline
\end{tabular}


Figura 15 - Análise das plantas da E2 pelos professores - 6 níveis

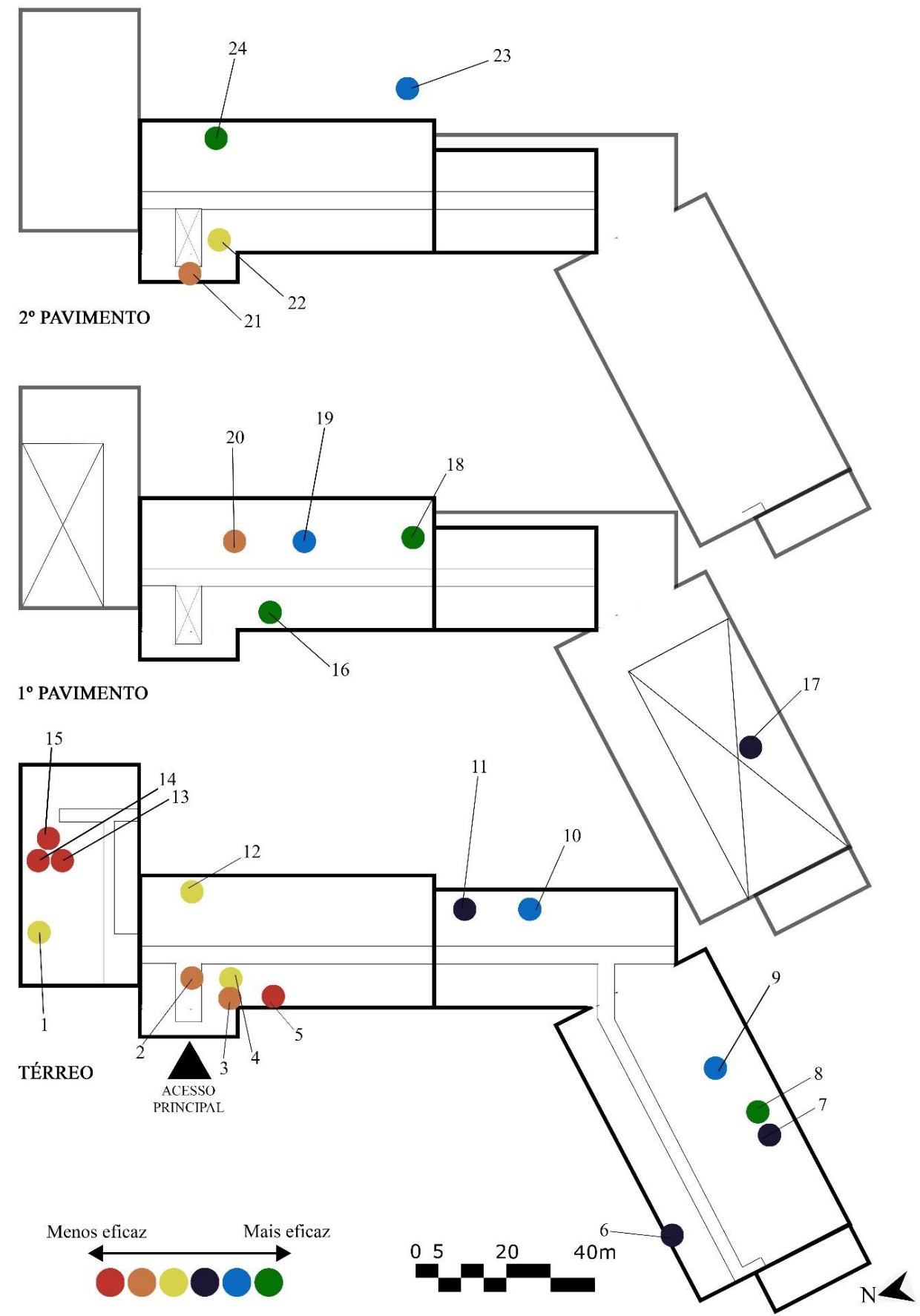


Figura 16 - Observações numeradas de acordo com a Figura 15 - comentários 1 a 14

\begin{tabular}{|c|c|c|c|}
\hline Número & Nível & Local & Comentários \\
\hline 1 & & Refeitório & $\begin{array}{l}\text { Muita altura, o espaço poderia ser melhor } \\
\text { usado }\end{array}$ \\
\hline 2 & & Átrio & $\begin{array}{l}\text { O átrio parece ótimo, mas talvez o espaço } \\
\text { poderia ser melhor usado }\end{array}$ \\
\hline 3 & & Sala de reflexão & $\begin{array}{l}\text { A sala de reflexão é muito pequena e } \\
\text { precisamos de um espaço maior para } \\
\text { acomodar mais alunos que foram removidos } \\
\text { de suas lições habituais }\end{array}$ \\
\hline 4 & & Sala de reflexão & $\begin{array}{l}\text { Sala de reflexão muito pequena } \\
\text { /apertada Precisa de um lugar maior e } \\
\text { móveis extras. Muito escuro; opressivo }\end{array}$ \\
\hline 5 & & Sala de conexão & $\begin{array}{l}\text { Não é usado como sala de aula, é pequeno } \\
\text { demais para } 18 \text { alunos }+2 \text { adultos }\end{array}$ \\
\hline 6 & & Vestiário & $\begin{array}{l}\text { Vestiário bem colocado, MAS abre direto } \\
\text { para a área externa / falta de privacidade }\end{array}$ \\
\hline 7 & & $\begin{array}{l}\text { Quadra e Salão } \\
\text { Principal }\end{array}$ & $\begin{array}{l}\text { Quadra de esportes e Salão Principal - } \\
\text { grande e maravilhosa área para esportes e } \\
\text { assembleias / parede divisória é uma } \\
\text { excelente característica }\end{array}$ \\
\hline 8 & & $\begin{array}{l}\text { Quadra e Salão } \\
\text { Principal }\end{array}$ & $\begin{array}{l}\text { Espaçoso / leve / útil área funcional / } \\
\text { excelente espaço }\end{array}$ \\
\hline 9 & & $\begin{array}{l}\text { Quadra e Salão } \\
\text { Principal }\end{array}$ & $\begin{array}{l}\text { Acústica eficaz. A parede divisória torna o } \\
\text { espaço muito flexível. Fechamento das } \\
\text { janelas superiores para controlar iluminação }\end{array}$ \\
\hline 10 & & $\begin{array}{l}\text { Laboratórios de } \\
\text { Ciências }\end{array}$ & $\begin{array}{l}\text { Laboratório de ciências especializado - } \\
\text { ótimo ter laboratório com grandes espaços } \\
\text { para biologia, química e física }\end{array}$ \\
\hline 11 & & $\begin{array}{l}\text { Laboratórios de } \\
\text { Ciências }\end{array}$ & $\begin{array}{l}\text { O layout do laboratório é muito mais } \\
\text { agradável que o do antigo edifício; espaçoso } \\
\text { para o movimento durante experimentos e } \\
\text { armazenamento incorporado com mesas de } \\
\text { laboratório Luz natural }\end{array}$ \\
\hline 12 & & Biblioteca & Não idealmente situado para acesso / ensino \\
\hline 13 & & Auditório & $\begin{array}{l}\text { Multifuncional, mas a organização para o } \\
\text { almoço limita a disponibilidade }\end{array}$ \\
\hline 14 & & $\begin{array}{l}\text { Refeitório e } \\
\text { Auditório }\end{array}$ & $\begin{array}{l}\text { O espaço está muito alto (vão) / Poderia } \\
\text { haver um mezanino ou um andar completo } \\
\text { acima. É muito difícil usar o espaço para o } \\
\text { ensino devido às instalações do refeitório }\end{array}$ \\
\hline
\end{tabular}


Figura 17 - Observações numeradas de acordo com a Figura 15 - comentários 15 a 24

\begin{tabular}{|c|c|c|c|}
\hline Número & Nível & Local & Comentários \\
\hline 15 & & Auditório & $\begin{array}{l}\text { Uso limitado além do almoço / intervalos / } \\
\text { assembleias - subutilizados. O teto deveria } \\
\text { ter sido fechado para permitir um espaço } \\
\text { mais flexível }\end{array}$ \\
\hline 16 & & $\begin{array}{l}\text { Sala de } \\
\text { Humanidades } 23\end{array}$ & $\begin{array}{l}\text { Sala de aula grande e bem projetada, com } \\
\text { muito espaço para armazenamento }\end{array}$ \\
\hline 17 & & Quadras & $\begin{array}{l}\text { Grande pavilhão desportivo, mas com muita } \\
\text { altura - o espaço pode ser usado para outras } \\
\text { atividades }\end{array}$ \\
\hline 18 & & Sala de Artes 28 & $\begin{array}{l}\text { Sala ampla, espaço flexível e móveis } \\
\text { grandes Aberta, espaçosa, com acesso à } \\
\text { varanda Luz natural e vistas inspiradoras As } \\
\text { exposições nas paredes inspiram }\end{array}$ \\
\hline 19 & & Salas de Artes & $\begin{array}{l}\text { Adoráveis salas de arte que estimulam a } \\
\text { criatividade }\end{array}$ \\
\hline 20 & & Sala de Estudos & $\begin{array}{l}\text { Preferiria que houvesse mais móveis de sala } \\
\text { de aula, que poderiam ser movidos mais } \\
\text { facilmente para diferentes aulas; Não há } \\
\text { muito espaço de armazenamento }\end{array}$ \\
\hline 21 & & $\begin{array}{l}\text { Suporte } \\
\text { Informática }\end{array}$ & $\begin{array}{l}\text { Espaço de escritório fechado por salas de } \\
\text { aula }\end{array}$ \\
\hline 22 & & $\begin{array}{l}\text { Laboratórios de } \\
\text { Informática }\end{array}$ & $\begin{array}{l}\text { As salas de ICT no } 1 \% \text { e } 2 \circ \text { andar foram } \\
\text { fantásticos quando se mudaram pela } \\
\text { primeira vez em } 2009 \text {, mas devido às } \\
\text { mudanças curriculares e mudanças nas } \\
\text { tecnologias agora o uso de espaço e recursos } \\
\text { é menos eficaz }\end{array}$ \\
\hline 23 & & $\begin{array}{l}\text { Posição da } \\
\text { escola/janelas }\end{array}$ & $\begin{array}{l}\text { Vista / tamanho / layout das salas de aula de } \\
\text { frente para o mar }\end{array}$ \\
\hline 24 & & Varandas & $\begin{array}{l}\text { Varandas como luxo para as escolas em } \\
\text { geral, especialmente para apreciar a vista } \\
\text { sobre o mar / bem-estar / construção mais } \\
\text { esteticamente agradável }\end{array}$ \\
\hline
\end{tabular}

\section{Discussão}

Observou-se que as escolas apresentam muitas das características consideradas importantes para edifícios educacionais. A reforma da E1 e a nova construção da E2 demonstra preocupação de atualização dos conceitos de projeto para ambientes escolares, mesmo sem o conhecimento direto dos PPs apresentados na pesquisa. Contudo, alguns desses aspectos podem ser ajustados de forma ainda mais adequada quando são realizadas análises APOs como as demonstradas neste estudo.

Nota-se que os usuários conseguem perceber as características relacionadas aos PPs, e que estes fazem falta quando não existem. Além disso, percebe-se a importância de um levantamento detalhado feito por especialista que corrobora com as descrições oferecidas pelos usuários. A análise específica da presença dos PPs nessas escolas permite uma discussão mais aprofundada sobre questões arquitetônicas, como, por exemplo, soluções projetuais para múltiplas inteligências, e reforços aos aspectos de conforto.

A atividade de ranqueamento permitiu que os estudantes se envolvessem ativamente na discussão, sendo possível afirmar que os alunos definiram como mais significativas as características relacionadas a parâmetros ainda não presentes na escola, o que mostra um desejo de acesso a ambientes com esses aspectos. Para eles, as cores estimulam, bem como o mobiliário e a iluminação. As observações sobre transparências contribuem para uma análise relacionada às conexões interiores - e entre esses espaços e o exterior. Uma vez que esta característica foi considerada positiva nas imagens, trabalhar com ela e outros tipos de conexões visuais e físicas em projetos futuros pode significar maior satisfação e motivação com relação ao uso do edifício. Essa característica também contribui para a proteção e segurança dos alunos (controle visual passivo). 
Essas opiniões ampliam o escopo de metodologias APO e o tipo de abordagem para alcançá-las se mostrou eficiente. Entretanto, é necessário ressaltar que a seleção das imagens deve ser cuidadosa. Nesta pesquisa procurou-se incluir nas imagens um número máximo de parâmetros quanto possível como guia para apresentar multiplicidade de soluções arquitetônicas, com presença dos alunos dentro da faixa etária pesquisada. Assim, indica-se também que sempre seja justificada a seleção das imagens ao ser utilizado esse instrumento para uma análise mais precisa dos resultados.

As análises por plantas apontam espaços que se destacam pelo seu aspecto funcional. Foram indicadas características relativas aos PPs. A análise negativa dos corredores, considerados espaços ineficazes, em ambos os casos, está ligada ao modo como esses espaços são usados: locais de passagem, sem aproveitamento de potencialidades como espaços de aprendizagem informal, o que se conecta a parâmetros como watering hole e cave space, ou projetos para múltiplas inteligências.

Os parâmetros de transparência e conexão externa-interna são estímulos à conexão física e visual dos espaços, auxiliando trocas de aprendizagem e colaboração. A escolha da aplicação da análise de 2 ou 6 níveis fica a critério do especialista, mas o emprego de ambas em uma mesma escola facilita uma análise geral e, em seguida, um levantamento específico da escola. Independentemente da escolha, essa aplicação traz a realidade dos usuários como pauta de discussão na pesquisa, o que é essencial.

\section{Considerações finais}

A compreensão pela APO de preferências e comportamentos humanos auxilia a elaboração de projetos mais conectados às necessidades contemporâneas. Uma das maneiras de coleta dessas informações é através de atividades participativas e aplicação de métodos visuais como neste estudo. Estes se mostraram válidos e facilitaram a expressão dos pontos desejados e valorizados pelos usuários, bem como auxiliaram na compreensão de aspectos das construções existentes.

Considera-se que cada método apresenta contribuições específicas à avaliação, acrescentando informações ao processo de programa arquitetônico escolar. A partir deste estudo, indica-se a aplicação dos instrumentos apresentados na ordem destacada no Quadro 1: walkthrough, análise de parâmetros, diamond ranking, análise de plantas -2 níveis, análise de plantas -6 níveis. Dados coletados em APOs objetivam a produção mais eficiente de soluções e quanto mais aprofundado e maior espaço amostral na aplicação das metodologias, mais informações são levantadas, o que facilita a identificação de demandas. Esses métodos não substituem levantamentos oriundos de outras metodologias de APO.

Dessa forma, este estudo contribuiu para expandir os métodos de APO, incluindo instrumentos visuais que fazem uso de materiais físicos e pré-concebidos (imagens para manusear; plantas para serem analisadas com marcadores adesivos). Esse tipo de instrumento torna a atividade lúdica, mais eficaz e com resultados específicos controlados. Esta pesquisa demonstra também ser possível, a partir do conceito contemporâneo de PPs, guiar os especialistas na organização e avaliação dos instrumentos de levantamentos APO e de análise dos resultados.

Pesquisas no sentido de compreender o uso dos parâmetros no processo de projeto também podem aprofundar análises que relacionam esses elementos aos requisitos de desempenho de referências normativas, buscando observar como os PPs podem auxiliar no pensamento e inclusão de elementos essenciais das normas. Adicionalmente, os métodos com elementos visuais descritos e aplicados neste estudo poderão ser usados em outros contextos com a inclusão de parâmetros específicos, atestando seu potencial de adaptabilidade e valor para ampliação do conhecimento de estudos sobre o processo de projeto em arquitetura.

\section{Referências}

AFASIA. Henley Halebriwn. 2019. Disponível em: https://afasiaarchzine.com/2019/09/henley-halebrown/. Acesso em: 15 dez. 2019.

ALEXANDER, C.; ISHIKAWA, S.; SILVERSTEIN, M. A pattern language: towns, buildings, construction. New York: Oxford University Press, 1977.

ARCHDAILY. Hight tech chula vista / Studio E Architects. Disponível em: https://www.archdaily.com/130879/high-tech-high-chula-vista-studio-e-architects/. Acesso em: 15 dez. 2019. 
ARCHITIZER. AOC Oost Twello. Disponível em: https:architizer.com/projects/oac-oost-twello/. Acesso em: 9 maio 2020.

ARCHITRAVEL. OrestadCollege. Disponível em: http://www.architravel.com/architravel/building/orestad-college/. Acesso em: 15 dez. 2019.

AZEVEDO, G. A. N. Sobre o papel da arquitetura escolar no cotidiano da educação: análise das interações pessoa-ambiente para a transformação qualitativa do lugar pedagógico. In: ENCONTRO NACIONAL DE TECNOLOGIA DO AMBIENTE CONSTRUÍDO, 14., Juiz de Fora., 2012.Anais [...] Juiz de Fora: ANTAC, 2012.

AZEVEDO, G. A. N.; BASTOS, L. E. G.; BLOWER, H. S. Escolas de ontem, educação hoje: é possível atualizar usos em projetos padronizados? Cadernos PROARQ, p. 59, 2007.

BARRETT, P. et al. The holistic impact of classroom spaces on learning in specific subjects. Environment and Behavior, p. 1-27, maio 2016.

CLARK, J. et al. Making connections: theory and practice of using visual methods to aid participation in research. Newcastle upon Tyne: Research Centre for Leaning and Teaching, 2013.

CLEMENTS-CROOME, D. The role of feedback in building design 1980-2018 and onwards. Building Services EngineeringResearchand Technology, v. 9, nov. 2018.

DELIBERADOR, M. S. Parâmetros da arquitetura escolar e o jogo de cartas como ferramenta de apoio ao desenvolvimento do programa arquitetônico. Campnas, 2016. Tese (Doutorado em Engenharia Civil) - Faculdade de Engenharia Civil e Arquitetura, Universidade Estadual de Campinas, Campinas. 2016.

DEXIGNER. NBCS: the school of the Future by WMK Architecture. 2016. Disponível em: https://www.dexigner.com/news/28906. Acesso em: 15 dez. 2019.

DUDEK, M. Architecture of schools: the new learning environment. Oxford: Architectural Press, 2000.

ELALI, G. A.; VELOSO, M. Avaliação pós-ocupação e processo de concepção projetual em arquitetura: uma relação a ser melhor compreendida. In: SEMINÁRIO INTERNACIONAL, São Paulo, 2006. Anais [...] São Paulo, 2006.

FRANÇA, A. J. G. L. Ambientes contemporâneos para o ensino-aprendizagem: avaliação pós-ocupação aplicada a três edifícios escolares públicos, situados na região metropolitana de São Paulo. São Paulo, 2011. Dissertação (Mestrado em Engenharia Civil) - Faculdade de Arquitetura e Urbanismo, Universidade de São Paulo, São Paulo, 2011.

GARDNER, H. Multiple intelligences: new horizons. Nova York: Basic Books, 2006.

GIFFORD, R. (ed.). Research methods for environmental psychology.Hoboken: Wiley-Blackwell, 2016.

GRANJA, A. D. et al. A natureza do valor desejado na habitação social. Ambiente Construído, Porto Alegre, v. 9, n. 2, p. 87-103, abr./jun. 2009.

GÜNTHER, H.; ELALI, G. A.; PINHEIRO, J. Q. A abordagem multimétodos em estudos pessoaambiente: características, definições e implicações: métodos de pesquisa nos estudos pessoa-ambiente, $v$. 1, p. 369-380, 2008. Disponível em: http://www.beco-do-bosque.net/XTextos/23InterTransMulti.pdf. Acesso em: 9 out. 2016.

GÜNTHER, H.; PINHEIRO, J. Q.; GUZZO, R. S. L. psicologia ambiental: entendendo as relações do homem com seu ambiente. 3 ed. Campinas: Alínea, 2015.

HARPER, D. Talking about pictures: a case for photo elicitation. Visual Studies, v. 17, n. 1, p. 13-26, jan. 2002.

KALUNGA OKNAKOMFORTA. OfisnyeDveri. Disponível em: http://kaluga.oknakomforta.ru/produkcija/aluminievye-dveri/ofisnye-dveri/. Acesso em: 15 dez. 2019.

KIM, T. W.; CHA, S.; KIM, Y. Space choice, rejection and satisfaction in university campus. Indoor and Built Environment, v. 24, ago. 2016.

KOWALTOWSKI, D. C. C. K. Arquitetura escolar: o projeto do ambiente de ensino. São Paulo: Oficina de Textos, 2011. 
KOWALTOWSKI, D. C. C. K.; MOREIRA, D. de C. O programa arquitetônico. In: KOWALTOWSKI, D. C. C. K. et al. (ed.). O processo de projeto em arquitetura: da teoria à tecnologia. São Paulo: Oficina de Textos, 2011.

KUMLIN, R. Architectural programming: creative techniques for design professionals. New York: McGraw-Hill, 1995.

LAWSON, B. Como arquitetos e designers pensam. São Paulo: Editora Oficina de Textos, 2011.

LE, A. T. H. et al. refurbishment for school buildings: a literature review. International Journal of Building Pathology and Adaptation, v. 11, jun. 2018.

MOREIRA, D. de C. Os princípios da síntese da forma e a análise de projetos arquitetônicos. Campinas, 2007. Tese (Doutorado em Engenharia Civil) - Faculdade de Engenharia Civil, Arquitetura e Urbanismo, Universidade Estadual de Campinas, Campinas, 2007.

NAIR, P.; FIELDING, R.; LACKNEY, J.The language of school design: design patterns for 21st century schools. Minneapolis: DesignShare, 2013.

ONO, R. et al. (ed.). Avaliação Pós-Ocupação (APO) na Arquitetura, no Urbanismo e no Design: da Teoria à Prática. São Paulo: Oficina de Textos, 2018.

ORNSTEIN, S. W. et al. Improving the quality of school facilities through building performance assessment: educational reform and school building quality in São Paulo, Brazil. Journal of Educational Administration, v. 47, n. 3, p. 350-367, maio 2009.

PERKINS EASTMAN. Chengdu International School. Disponível em: http://www.perkinseastman.com/print_project_3418807_chengdu_international_school. Acesso em: 15 dez. 2019.

PFLUGER ARCHITECTS. Cedar Creek High School. Disponível em: http://www.pflugerarchitects.com/project/cedar-creek-high-school. Acesso em: 15 dez. 2019.

PROSSER, J. Visual methods and the visual culture of schools. Visual Studies, v. 22, n. 1, p. 13-30, abr. 2007.

RHEINGANTZ, P. A. et al. Observando a qualidade do lugar: procedimentos para a avaliação pósocupação. Rio de Janeiro: Proarq/FAU/UFRJ, 2009.

RYAN, M. C. PEGS Junior Boys School. Disponível em: https://www.archdaily.com/161388/pegs-juniorboys-school-mcbride-charles-ryan. Acesso em: 15 dez. 2019.

SANOFF, H. Visual research methods in design. New York: Van Nostrand Reinhold, 1991.

SOUZA, L. N. de. Arquitetura escolar, parâmetros de projeto e modalidades de aprendizagem. Campinas, 2018. Dissertação (Mestrado em Engenharia Civil) - Faculdade de Engenharia Civil e Arquitetura, Universidade Estadual de Campinas, Campinas, 2018.

TAYLOR, A. P. Linking architecture and education: sustainable design for learning environments. New Mexico: Universityof New Mexico Press, 2009.

VAN DER VOORDT, T. J. M.; VAN WEGEN, H. B. R. Arquitetura sob o olhar do usuário: programa de necessidades, projeto e avaliação de edificações. São Paulo: Oficina de Textos, 2013.

VELOSO, L.; MARQUES, J. S. Designing science laboratories: learning environments, school architecture and teaching and learning models. Learning Environments Research, v. 20, n. 2, p. 221-248, jul. 2017.

VILLA, S. B.; SARAMAGO, R. C. P.; GARCIA, L. C. Desenvolvimento de Metodologia de Avaliação Pós-Ocupação do Programa Minha Casa Minha Vida: aspectos funcionais, comportamentais e ambientais. Brasília: IPEA, 2016.

WHITE, E. T. Introduction to architectural programming. Tucson: Architectural Media, 1972.

WOOLNER, P. et al. Getting together to improve the school environment: user consultation, participatory design and student voice. ImprovingSchools, v. 10, n. 3, p. 233-248, nov. 2007.

WOOLNER, P. et al. Pictures are necessary but not sufficient: using a range of visual methods to engage users about school design. Learning Environments Research, v. 13, n. 1, p. 1-22, mar. 2010. 


\section{Agradecimentos}

À Fapesp: Processos n. 2016/11479-3 e 2016/25514-0, ao CfLaT e às escolas dos estudos de caso.

\section{Larissa Negris de Souza}

Faculdade de Engenharia Civil, Arquitetura e Urbanismo | Universidade Estadual de Campinas | Rua Saturnino de Brito, 224 | Campinas SP - Brasil | CEP 13083-889 | Te.: (27)99299-4438 | E-mail: larissanegris@gmail.com

Doris Catharine CornelieKnatzKowaltowski

Faculdade de Engenharia Civil, Arquitetura e Urbanismo | Universidade Estadual de Campinas | Tel.: (19)3521-2390 | E-mail:

dkowaltowski@gmail.com

\section{Pamela Woolner}

School of Education, Communication and Language Sciences | Newscastle University | King George VI Building, Queen Victoria Road | Newcastle upon Tyne -UK | NE1 7RU | Tel.: +44 (0) 191 208-5470 | E-mail: pamela.woolner@ncl.ac.uk

\section{Ambiente Construído}

Revista da Associação Nacional de Tecnologia do Ambiente Construído

Av. Osvaldo Aranha, $99-3^{\circ}$ andar, Centro

Porto Alegre - RS - Brasil

CEP $90035-190$

Telefone: +55 (51) 3308-4084

Fax: +55 (51) 3308-4054

www.seer.ufrgs.br/ambienteconstruido

E-mail: ambienteconstruido@ufrgs.br

(c) (i)

This is an open-access article distributed under the terms of the Creative Commons Attribution License. 